This document is confidential and is proprietary to the American Chemical Society and its authors. Do not copy or disclose without written permission. If you have received this item in error, notify the sender and delete all copies.

\title{
Phenyl(thio)phosphon(amid)ate Benzenesulfonamides as Potent and Selective Inhibitors of Human Carbonic Anhydrases II and VII Counteract Allodynia in a Mouse Model of Oxaliplatin-Induced Neuropathy
}

\begin{tabular}{|c|c|}
\hline Journal: & Journal of Medicinal Chemistry \\
\hline Manuscript ID & jm-2019-02135g.R4 \\
\hline Manuscript Type: & Article \\
\hline $\begin{array}{r}\text { Date Submitted by the } \\
\text { Author: }\end{array}$ & 29-Apr-2020 \\
\hline Complete List of Authors: & $\begin{array}{l}\text { Nocentini, Alessio; Universita degli Studi di Firenze, Neurofarba } \\
\text { ALTERIO, VINCENZO; CNR, IBB } \\
\text { Bua, Silvia; Universita degli Studi di Firenze, Neurofarba } \\
\text { Micheli, Laura; Universita degli Studi di Firenze, Dipartimento di } \\
\text { Neuroscienze, Area del Farmaco e Salute del Bambino (NEUROFARBA) } \\
\text { Esposito, Davide; IBBR CNR Naples } \\
\text { Buonanno, Martina; Italian National Research Council, Istituto di } \\
\text { Biostrutture e Bioimmagini } \\
\text { Bartolucci, Gianluca; University of Florence, Neurofarba } \\
\text { Osman, Sameh M.; King Saud University } \\
\text { ALOthman, Zeid; King Saud University, Chemistry } \\
\text { Cirilli, Roberto; Istituto Superiore di Sanita, Centro Nazionale per il } \\
\text { Controllo e la Valutazione dei farmaci } \\
\text { Pierini, Marco; Universita degli Studi di Roma La Sapienza, Dipartimento } \\
\text { di Chimica e Tecnologie del Farmaco } \\
\text { Monti, Simona; Italian National Research Council, Istituto di Biostrutture } \\
\text { e Bioimmagini } \\
\text { Di Cesare Mannelli, Lorenzo; Universita degli Studi di Firenze, } \\
\text { Dipartimento di Farmacologia Preclinica e Clinica } \\
\text { Gratteri, Paola; University of Firenze, Department of NEUROFARBA, } \\
\text { Pharmaceutical \& Nutraceutical Section } \\
\text { Ghelardini, Carla; Universita degli Studi di Firenze, Dipartimento di } \\
\text { Farmacologia } \\
\text { De Simone, Giuseppina; Italian National Research Council, Istituto di } \\
\text { Biostrutture e Bioimmagini } \\
\text { Supuran, Claudiu; Università degli Studi di Firenze, Dipartimento } \\
\text { Neurofarba }\end{array}$ \\
\hline
\end{tabular}

\section{SCHOLARONE" Manuscripts}




\title{
Phenyl(thio)phosphon(amid)ate Benzenesulfonamides as Potent and Selective Inhibitors of Human Carbonic Anhydrases II and VII Counteract Allodynia in a Mouse Model of Oxaliplatin-Induced Neuropathy
}

\author{
Alessio Nocentini ${ }^{\mathrm{a},}{ }^{*}$, Vincenzo Alterio ${ }^{\mathrm{b}}$, Silvia Bua ${ }^{\mathrm{a}}$, Laura Michelic ${ }^{\mathrm{c}}$, Davide Esposito ${ }^{\mathrm{b}}$, Martina \\ Buonanno $^{\mathrm{b}}$, Gianluca Bartoluccia, Sameh M. Osman ${ }^{\mathrm{d}}$, Zeid A. ALOthman ${ }^{\mathrm{d}}$, Roberto Cirillie, Marco \\ Pierinif $^{f}$ Simona Maria Monti ${ }^{b}$, Lorenzo Di Cesare Mannellic, Paola Gratteri ${ }^{\mathrm{a}}$, Carla Ghelardini ${ }^{\mathrm{c}}$, \\ Giuseppina De Simone ${ }^{\mathrm{b}}$, Claudiu T. Supuran ${ }^{\mathrm{a},}{ }^{*}$
}

${ }^{a}$ Department of NEUROFARBA, Pharmaceutical and Nutraceutical Section, University of Florence, Via Ugo Schiff 6, 50019 Sesto Fiorentino, Italy.
${ }^{b}$ Istituto di Biostrutture e Bioimmagini, CNR, Via Mezzocannone 16, 80134 Napoli, Italy.
${ }^{c}$ Department of NEUROFARBA, Pharmacology and Toxicology Section, University of Florence, Viale Pieraccini 6, 50139 Firenze, Italy.
${ }^{d}$ Chemistry Department, College of Science, King Saud University, P. O. Box 2455, Riyadh 11451, Saudi Arabia.
${ }^{e}$ Centro nazionale per il controllo e la valutazione dei farmaci, Istituto Superiore di Sanità, Viale Regina Elena 299,00161 Rome, Italy.
${ }^{f}$ Dipartimento di Chimica e Tecnologie del Farmaco, Sapienza University of Rome, P.le A. Moro 5, 00185 Rome, Italy.

\begin{abstract}
Human carbonic anhydrase (CA; EC 4.2.1.1) isoforms II and VII are implicated in neuronal excitation, seizures and neuropathic pain (NP). Their selective inhibition over off-target CAs is expected to produce an anti-NP action devoid of side effects due to promiscuous CA modulation. Here a drug-design strategy based on the observation of (dis)similarities between the target CA active sites was planned with benzenesulfonamide derivatives and, for the first time, a phosphorus-based linker. Potent and selective CA II-VII inhibitors were identified among the synthesized phenyl(thio)phosphon(amid)ates 3-22. X-ray crystallography depicted the binding mode of phosphonic acid 3 to both CA II and VII. The most promising derivatives, after evaluation of their stability in acidic media, were tested in a mouse model of oxaliplatin-induced neuropathy. The most potent compound racemic mixture was subjected to HPLC enantioseparation and the identification of the eutomer, the $(S)$-enantiomer, allowed to halve the dose totally relieving allodynia in mice.
\end{abstract}

Keywords: neuropathic pain; metalloenzyme; drug-design; phosphonate; phosphonamidate. 


\section{Introduction}

Neuropathic pain (NP) is pain initiated by a damage or ailment of the peripheral or central somatosensory system. ${ }^{1}$ The prevalence of NP in the population is estimated to be $6.9-10 \%$ and amounts to $20-25 \%$ of all chronic pain cases. ${ }^{2,3}$ Numbness, needles sensation and tingling, paresthesia and neurological sensory deficits are NP main symptoms which can occur both at the central and peripheral nervous system. Peripheral neuropathies can derive from viral infections, traumatic, postsurgical or diabetic neuropathies, while central pain syndromes are usual in patients which suffered by multiple sclerosis, spinal cord injury, or stroke. ${ }^{4}$ The syndromes can manifest in the form of spontaneous, continuous (or paroxysmal), or evoked pain. The latter can be in turn distinguished in hyperalgesia, in case it is initiated by painful stimuli and allodynia, if triggered by non-noxious stimuli. Neuropathic pain is challenging to treat because of the heterogeneity and complexity of signals and symptoms. Indeed, the use of traditional analgesics (e.g. NSAIDs) or weak opioids is associated to weak outcomes in NP patients as these drugs do not target the types of symptoms correlated with the disease. ${ }^{4}$ The lack of specific drugs for treating NP is partially overcome with serendipitously discovered agents of the anticonvulsant and antidepressant classes, though actually only $40-60 \%$ of patients attain satisfactory pain alleviation upon treatment. ${ }^{3}$ The first-line treatment comprises some types of antidepressants such as tricyclic antidepressants and dual norepinephrine/serotonin reuptake inhibitors, topical analgesics (lidocaine) and calcium channel $\alpha 2$ $\delta$ ligands as anticonvulsants (pregabalin and gabapentin). ${ }^{1,5-7}$ Second-line treatments are represented by effective opioids and tramadol, while other antidepressants, antiepileptics (among which topiramate, zonisamide, lacosamide), N-methyl-D-aspartate receptor antagonists, topical capsaicin and mexiletine can be used as third-line treatment. ${ }^{8-10}$ Alternative pharmacological strategies are being actually explored to overcome the difficulties met in the treatment of most NP patients. Among the numerous promising new targets/drug classes identified are histamine H4 receptor (H4R) agonists, agonists of type 1 lysophosphatidic acid receptor, glial cell activity modulators , $\mu$-opioid receptor (MOP) agonists, and carbonic anhydrase inhibitors. ${ }^{11-14}$ 
Carbonic anhydrases (CAs; EC 4.2.1.1) are widely expressed in the central nervous system and choroid plexus. ${ }^{15,16}$ Of the fifteen human (h) CAs, CA II is the most physiologically relevant isoform and is abundantly expressed in oligodendrocytes, myelin sheaths, astrocytes, choroid plexus, and myelinated tracts of brain. ${ }^{15,17}$ The membrane-bound CA IV is located in layers III and VI in thalamus hippocampus, and cortex, as well as on the luminal surface of cerebral capillaries present in the bloodbrain barrier. ${ }^{18}$ Likewise, CA VII is highly expressed in thalamus, hippocampus and cortex. CA VII is deemed a brain-associated CA isozyme as it is predominantly expressed in the CNS while missing in most other systems. ${ }^{15,18}$

The link between CAs and NP was recently established by the groups of Kaila and Price. ${ }^{19,20}$ The CA-catalysed production of $\mathrm{HCO}_{3}{ }^{-}$significantly affects the biochemistry and physiology of neurotransmitters, such as $\gamma$-aminobutyric acid (GABA). Injuries in peripheral nerves negatively impact spinal GABA-ergic networks by reducing the neuron-specific potassium-chloride $\left(\mathrm{K}^{+}-\mathrm{Cl}^{-}\right)$ cotransporter (KCC2). A potential strategy to mitigate this process was validated which implicates CA inhibition as it can decrease bicarbonate- related depolarization through GABAA receptors in case the KCC2 function is compromised. Moreover, Ruusuvuori et al. have provided insights into the role of CAs in the modulation of the neuronal signaling and showed that isoforms II and VII are the only cytosolic isozymes present in both somata and dendrites of mature CA1 pyramidal neurons. ${ }^{21,22}$ As CAs are implicated in maintaining the bicarbonate gradient that results in the efflux of $\mathrm{HCO}_{3}^{-}$ ions through GABAA receptors, this study corroborated the involvement of CA VII, as well as CA II, in neuronal excitation and seizures. ${ }^{21}$

Hence, a structure-based drug design strategy based on benzenesulfonamide derivatives including for the first time a phosphorus-based linker is here reported to provide potent and possibly selective CA II/VII inhibitors in search of new tools for the management of neuropathic pain.

\section{Results and Discussion}

Drug design and chemistry 
The spreading interest of novel therapeutic agents based on CA inhibition or continued validation of specific hCAs as drug targets requires that selective inhibitors are developed. ${ }^{23}$ However, all clinically used CAIs, among which primary sulfonamides and sulfamates investigated in the therapy of neuropathic pain such as acetazolamide, methazolamide, topiramate, zonisamide, celecoxib and furosemide, are predominantly non-selective with respect to all human isoforms. ${ }^{17}$ Most recent drugdesign studies on CAIs involved the tumor-associated CA IX and CA XII, and culminated with the entrance of the phenylureido benzenesulfonamide SLC-0111 in Phase Ib/II clinical trials for the treatment of advanced, metastatic solid tumors as a monotherapy or in combination with other agents such as gemcitabine..$^{23,24}$ In contrast, few compounds with pronounced inhibitory selectivity and/or potency toward hCA II and hCA VII have been reported to-date. ${ }^{23,25}$

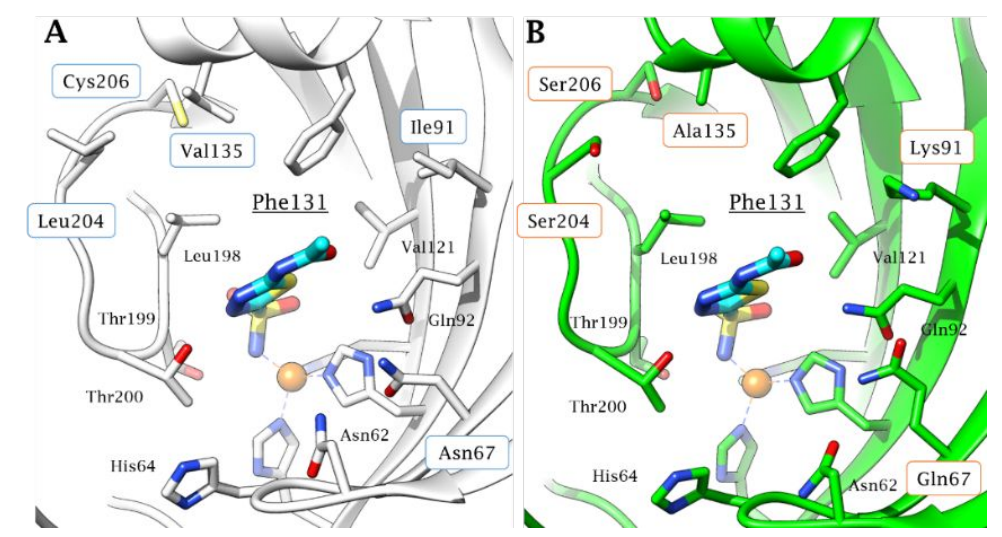

Figure 1. Comparison between the active site of A) hCA II (pdb 3HS4) and B) hCA VII (pdb 3ML5) in complex with acetazolamide (AAZ). Residues different between the two enzymes are boxed in blue for hCA II and orange for hCA VII. The target amino acid Phe131 from both active sites is underlined.

In this study, by observing the significant similarity in amino acid composition and active site architecture existing between hCA II and hCA VII (Figure 1) a new series of CAIs was designed, which can concomitantly target both isozymes with the aim of achieving a neuropathic pain-relieving action. ${ }^{15,26}$ 
A

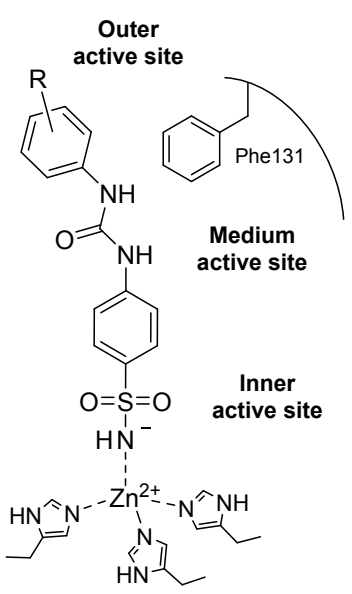

B

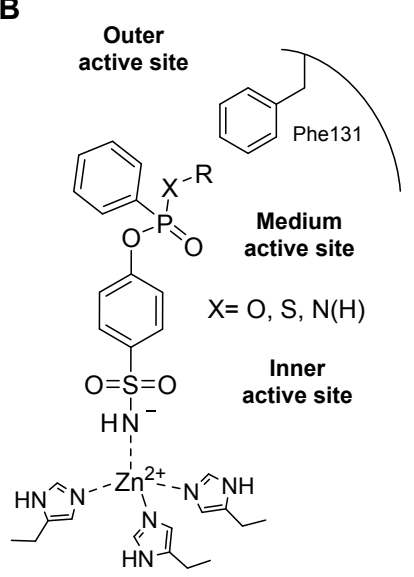

Figure 2. A) Schematic representation of phenylureidobenzenesulfonamides bound to CA II active site. B) Drug design of benzene (thio)phosphon(amid)ates as CA II and VII inhibitors.

In detail, CA II and CA VII share a Phe residue in position 131 (Figure 1). This residue is known to play an important role in the binding of many CAIs, ${ }^{26,27}$ and thus was taken as reference point to explore the chemical space in the middle portion of the CA active site, where differences exist between CA II and VII (Figure 2) as well as with other CA isoforms. Benzenesulfonamide derivatives were thus designed according to the tail approach that, in recent years, has been mainly applied by using urea-based linkers. ${ }^{23,26}$ Such an approach consists in appending a variety of chemical frameworks to the main CA inhibitory scaffold with the aim of diversely targeting the medium/outer regions of the CAs active sites, where most amino acid variability exists. ${ }^{23}$ Nonetheless, the arylureidobenzensulfonamide (Figure 2A) was not deemed to possess an easily accessible chemical versatility to include a variety of substituents for studying the binding to the active site middle region, that is nearby Phe131. In fact, such a scaffold has been chiefly adopted for exploring the chemical space in the outer region of the binding cavity. ${ }^{28,29}$ Hence, in this context a phosphorus-based linker (Figure 2B) was adopted for the following reasons: ${ }^{30}$ (i) because of the electronic properties of the phosphorus atom, an additional substituent can be included on the spacer while holding the benzenesulfonamide and the aromatic ring interacting with Phe131 (i.e. the outer ring of the benzenesulfonamide derivative in Figure 2B); (ii) the extra substituent is appended in the middle of the derivative structure, a suitable position for interaction with the medium portion of the binding 
cavity (Figure 2B); (iii) by using phenylphosphonic dichlorides as reagents a wide variety of substituents can be easily appended to the spacer in the form of (thio)phosphon(amid)ates; (iv) finally, the presence of a chiral center on the phosphorus atom could induce an enantiomeric binding mode.

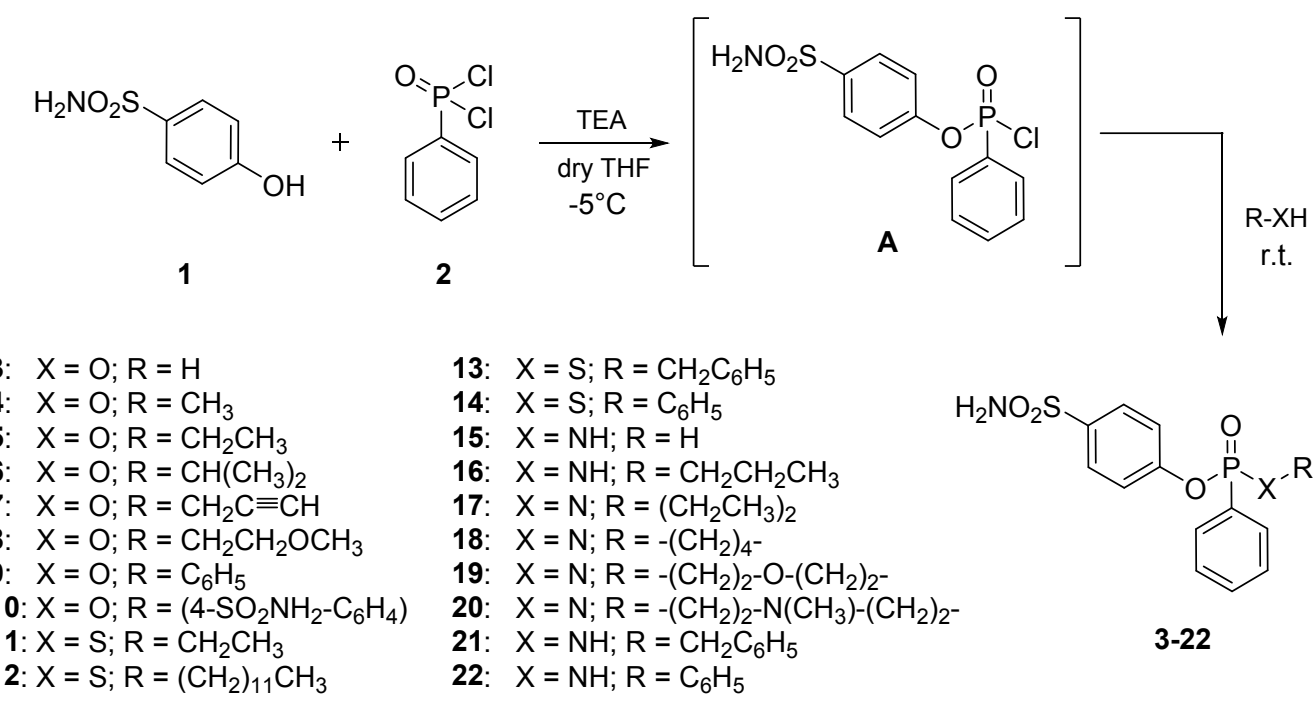

Scheme 1. Synthesis of (thio)phosphonates 3-14 and phosphonamidates 15-22.

On the basis of the drug design, a series of (thio)phosphon(amid)ates was designed and synthesized using 4-hydroxybenzenesulfonamide $\mathbf{1}$ and phenylphosphonic dichloride $\mathbf{2}$ as starting materials (Scheme 1). The choice of $\mathbf{1}$ in place of sulfanilamide, which is commonly derivatized to yield benzenesulfonamide series, was related to its major reactivity with phosphonic chlorides than the aromatic amine, thus producing higher yields as well as ease of purification. ${ }^{31}$ The snap addition of phenylphosphonic dichloride $\mathbf{2}$ to a solution of 4-hydroxybenzenesulfonamide $\mathbf{1}$ and triethylamine in anhydrous $\mathrm{THF}$ at $-5^{\circ} \mathrm{C}$ yielded intermediate $\mathbf{A}$. In contrast, a greater rate of double attack of $\mathbf{1}$ into phenylphosphonic dichloride was observed raising the temperature over r.t. and thus these conditions were used to achieve compound 10. Otherwise, the addition of various nucleophiles, among which (thio)alcohols, (thio)phenol, aliphatic and aromatic amines, to the reaction mixture containing $\mathbf{A}$ and stirring thereof at r.t. yielded (thio)phosphonates 3-9, 11-14 and phosphonamidates 15-22 (Table 1). The adopted synthetic pathway provided the compounds as racemic mixtures, with the exception of the bis-sulfonamide $\mathbf{1 0}$ and, when deprotonated, the phenylphosphonic acid $\mathbf{3}$. All derivatives were purified by column chromatography using silica gel and $\mathrm{MeOH} / \mathrm{DCM}$ gradients and fully 
characterized by ${ }^{1} \mathrm{H}-\mathrm{NMR},{ }^{13} \mathrm{C}-\mathrm{NMR},{ }^{31} \mathrm{P}-\mathrm{NMR}$ as well as HRMS (Supporting Information). According to literature data, peak picking of ${ }^{31} \mathrm{P}$ signals in NMR spectra reported the various ranges of signals given by phosphorus atoms of different types. ${ }^{31} \mathrm{P}$ signals of alkyl phosphonates 3-8 spanned from 14.31 to 16.73 ppm, while those of phosphonic acid $\mathbf{3}$ and aryl phosphonates $\mathbf{9}$ and $\mathbf{1 0}$ lied in the range 12.01-12.49 ppm. In contrast, ${ }^{31} \mathrm{P}$ signals of alkyl thiophosphonates 11-13 were found between 42.64 and $43.65 \mathrm{ppm}$, whereas the thiophenol derivative $\mathbf{1 4}$ showed a signal at $39.97 \mathrm{ppm}$. Primary and secondary phosphonamidates $\mathbf{1 5 - 1 7 , 2 1}$ reported ${ }^{31} \mathrm{P}$ peaks in the range $21.20-22.23$ ppm, the tertiary derivatives $\mathbf{1 8 - 2 0}$ between 18.85 and $19.65 \mathrm{ppm}$ and the aromatic amine derivative at $15.37 \mathrm{ppm}$.

\section{Carbonic anhydrase inhibition}

(Thio)phosphon(amid)ates 3-22 were evaluated for their inhibition against the cytosolic CA I, II and VII, the mitochondrial CA VA and VB and the membrane-associated CA IV, IX and XII by a stoppedflow method that measures $\mathrm{CO}_{2}$ hydrase activity. ${ }^{32} \mathrm{AAZ}$ was used as reference drug. The following SAR can be worked out from the data reported in Table 1.

Table 1: Inhibition data of human CA isoforms I, II, IV, VA, VB, VII, IX and XII with (thio)phosphon(amid)ates 3-22 and the standard acetazolamide (AAZ) by a stopped flow $\mathrm{CO}_{2}$ hydrase assay. ${ }^{32}$

\begin{tabular}{|c|c|c|c|c|c|c|c|c|}
\hline \multirow{2}{*}{ Cmp } & \multicolumn{8}{|c|}{$\mathbf{K}_{\mathrm{I}}{ }^{\mathrm{a}}(\mathbf{n M})$} \\
\hline & CA I & CA II & CA IV & CA VA & CA VB & CA VII & CA IX & CA XII \\
\hline 3 & $196.9 \pm 11.2$ & $37.9 \pm 2.1$ & $220.1 \pm 16.2$ & $76.3 \pm 5.2$ & $52.8 \pm 3.4$ & $16.1 \pm 1.1$ & $26.1 \pm 1.4$ & $30.8 \pm 2.3$ \\
\hline 4 & $494.9 \pm 35.4$ & $11.4 \pm 0.8$ & $259.2 \pm 14.5$ & $51.7 \pm 4.0$ & $24.3 \pm 1.5$ & $36.0 \pm 1.9$ & $16.2 \pm 0.9$ & $47.2 \pm 3.1$ \\
\hline 5 & $397.5 \pm 26.7$ & $36.6 \pm 2.4$ & $424.6 \pm 35.6$ & $142.6 \pm 8.3$ & $40.1 \pm 2.6$ & $38.2 \pm 2.5$ & $18.7 \pm 1.1$ & $22.4 \pm 1.5$ \\
\hline 6 & $307.8 \pm 18.1$ & $12.8 \pm 0.7$ & $1196 \pm 102$ & $100.8 \pm 5.9$ & $19.8 \pm 1.1$ & $6.2 \pm 0.4$ & $17.5 \pm 1.2$ & $42.0 \pm 3.2$ \\
\hline 7 & $415.3 \pm 29.0$ & $3.6 \pm 0.2$ & $1322 \pm 124$ & $82.1 \pm 5.7$ & $38.4 \pm 2.5$ & $12.2 \pm 0.8$ & $22.6 \pm 1.6$ & $26.7 \pm 1.8$ \\
\hline 8 & $779.7 \pm 44.8$ & $28.5 \pm 1.9$ & $1644 \pm 113$ & $59.3 \pm 4.1$ & $67.2 \pm 3.8$ & $25.0 \pm 1.2$ & $12.1 \pm 0.7$ & $35.7 \pm 2.8$ \\
\hline 9 & $971.1 \pm 62.7$ & $15.2 \pm 1.0$ & $2619 \pm 153$ & $470.4 \pm 33.6$ & $22.7 \pm 1.4$ & $31.4 \pm 1.8$ & $13.2 \pm 0.9$ & $24.6 \pm 1.9$ \\
\hline 10 & $670.7 \pm 40.1$ & $3.2 \pm 0.2$ & $360.3 \pm 29.5$ & $284.3 \pm 19.3$ & $15.0 \pm 0.9$ & $7.7 \pm 0.5$ & $19.7 \pm 1.4$ & $16.9 \pm 0.9$ \\
\hline 11 & $726.7 \pm 49.3$ & $30.2 \pm 2.1$ & $1389 \pm 89$ & $94.3 \pm 5.8$ & $96.7 \pm 5.7$ & $41.5 \pm 2.8$ & $27.0 \pm 2.0$ & $34.1 \pm 2.5$ \\
\hline 12 & $8345 \pm 552$ & $234.1 \pm 15.3$ & $4164 \pm 342$ & $641.9 \pm 45.7$ & $224.6 \pm 13.4$ & $100.8 \pm 6.3$ & $51.2 \pm 3.6$ & $47.8 \pm 3.4$ \\
\hline
\end{tabular}




\begin{tabular}{|c|c|c|c|c|c|c|c|c|}
\hline $\mathbf{1 3}$ & $3264 \pm 258$ & $64.8 \pm 3.7$ & $4456 \pm 298$ & $150.7 \pm 10.4$ & $58.4 \pm 4.1$ & $75.5 \pm 5.7$ & $25.0 \pm 1.6$ & $21.3 \pm 1.6$ \\
\hline $\mathbf{1 4}$ & $1635 \pm 101$ & $34.9 \pm 2.3$ & $2633 \pm 186$ & $382.0 \pm 26.5$ & $28.7 \pm 1.6$ & $15.7 \pm 1.2$ & $6.6 \pm 0.4$ & $39.2 \pm 2.5$ \\
\hline $\mathbf{1 5}$ & $195.1 \pm 15.7$ & $17.9 \pm 1.0$ & $292.4 \pm 22.1$ & $41.3 \pm 3.2$ & $12.6 \pm 0.8$ & $18.9 \pm 1.0$ & $20.9 \pm 1.2$ & $15.4 \pm 0.8$ \\
\hline $\mathbf{1 6}$ & $759.4 \pm 57.2$ & $26.2 \pm 1.6$ & $1516 \pm 99$ & $85.2 \pm 6.2$ & $33.7 \pm 2.4$ & $20.8 \pm 1.4$ & $3.2 \pm 0.2$ & $17.3 \pm 0.9$ \\
\hline $\mathbf{1 7}$ & $521.3 \pm 37.5$ & $17.5 \pm 1.1$ & $371.1 \pm 26.4$ & $106.8 \pm 5.9$ & $49.1 \pm 2.7$ & $13.5 \pm 0.8$ & $19.5 \pm 1.4$ & $46.8 \pm 3.1$ \\
\hline $\mathbf{1 8}$ & $242.1 \pm 18.6$ & $1.7 \pm 0.1$ & $307.6 \pm 19.2$ & $78.3 \pm 4.7$ & $25.6 \pm 1.3$ & $9.3 \pm 0.6$ & $28.9 \pm 2.1$ & $58.1 \pm 4.5$ \\
\hline $\mathbf{1 9}$ & $317.9 \pm 17.0$ & $7.9 \pm 0.5$ & $120.1 \pm 8.3$ & $43.9 \pm 3.1$ & $27.4 \pm 1.6$ & $30.5 \pm 2.4$ & $11.1 \pm 0.6$ & $27.6 \pm 1.3$ \\
\hline $\mathbf{2 0}$ & $390.8 \pm 29.6$ & $9.1 \pm 0.6$ & $76.9 \pm 5.2$ & $164.1 \pm 12.5$ & $47.3 \pm 3.4$ & $17.0 \pm 1.3$ & $61.9 \pm 5.1$ & $25.3 \pm 1.4$ \\
\hline $\mathbf{2 1}$ & $1705.9 \pm 117$ & $52.9 \pm 2.9$ & $643.9 \pm 46.2$ & $59.1 \pm 4.0$ & $68.7 \pm 4.8$ & $15.4 \pm 1.0$ & $2.6 \pm 0.2$ & $19.7 \pm 1.2$ \\
\hline $\mathbf{2 2}$ & $817.9 \pm 62.4$ & $2.4 \pm 0.1$ & $859.9 \pm 58.3$ & $184.6 \pm 14.1$ & $24.0 \pm 1.5$ & $5.5 \pm 0.3$ & $19.6 \pm 1.1$ & $20.9 \pm 1.3$ \\
\hline $\mathbf{A A Z}$ & $250 \pm 15$ & $12 \pm 1$ & $74 \pm 6$ & $63 \pm 4$ & $54 \pm 3$ & $2.5 \pm 0.2$ & $25 \pm 2$ & $5.7 \pm 0.5$ \\
\hline
\end{tabular}

a. Inhibition data are expressed as means \pm SEM of three different assays.

Overall, the adopted structure-based drug design strategy produced a satisfactory result in terms of inhibition potency against the targets CA II and VII, as well as selectivity over the other ubiquitous and off-target isoform CA I. The latter isozyme was in fact feebly inhibited by (thio)phosphon(amid)ates 3-22 with $\mathrm{K}_{\mathrm{I}} \mathrm{S}$ (inhibition constants) spanning in the high nanomolar up to low micromolar range $(195.1-8345 \mathrm{nM})$. The phosphonic acid $\mathbf{3}$ and the primary phosphonamidate 15 stood out as the most potent CA I inhibitors, presumably because of the low steric hindrance produced within one of the narrowest active sites among hCAs. As a matter of fact, compounds bearing phenyl $(\mathbf{9}, \mathbf{1 4}$ and 22) and benzyl (13 and 21) R groups as well as the lauryl derivative $\mathbf{1 2}$ acted as the weakest CA I inhibitors ( $\left.\mathrm{K}_{\mathrm{I}} \mathrm{S} 817.9-8345 \mathrm{nM}\right)$.

The target CA II was effectively inhibited by compounds 3-22 with $\mathrm{K}_{\mathrm{I}} \mathrm{s}$ below $100 \mathrm{nM}\left(\mathrm{K}_{\mathrm{I}} \mathrm{s} 1.7-64.8\right.$ $\mathrm{nM})$, except for derivative 12 which showed again the lowest $C A$ inhibition $\left(K_{I}\right.$ of $\left.234.1 \mathrm{nM}\right) . \mathrm{K}_{\mathrm{I}} \mathrm{s}$ even below $10 \mathrm{nM}$ were exhibited by propargyl and bis-sulfamoyl phosphonates 7 and 10, and phosphonamidates bearing a pyrrolidine (18), morpholine (19), N-methylpiperazine (20) and aniline (22). It should be noted that all other compounds inhibit CA II with $\mathrm{K}_{\mathrm{I}} \mathrm{s}$ below $50 \mathrm{nM}$ with the exceptions of the benzyl derivatives 13 and $21\left(\mathrm{~K}_{\mathrm{I}} \mathrm{S}\right.$ of 64.8 and $\left.52.9 \mathrm{nM}\right)$.

SAR of compounds 3-22 against CA IV is rather flat. This isozyme was the least inhibited by the new reported derivatives, most of which did not inhibit CA IV up to $500 \mathrm{nM} . \mathrm{K}_{\mathrm{I}} \mathrm{s}$ lying in the range 120- 
$450 \mathrm{nM}$ were however estimated for phosphonates 3-5, 10 and phosphonamidates 15, 17-19 whereas N-methylpiperazine 20 uniquely achieved a $\mathrm{K}_{\mathrm{I}}$ of $76.9 \mathrm{nM}$.

The mitochondrial CAs VA and VB show two distinct level of inhibition with compounds 3-22. While CA VB was inhibited in comparable range with CA II ( $\mathrm{K}_{\mathrm{I}}$ s between 12.6 and $\left.224.6 \mathrm{nM}\right)$, a drop of inhibition was measured for CA VA $\left(\mathrm{K}_{\mathrm{I}} \mathrm{S}\right.$ of 41.3-641.9 $\left.\mathrm{nM}\right)$, but without approaching the high nanomolar to low micromolar $\mathrm{K}_{\mathrm{I}} \mathrm{S}$ detected against CA I and IV. Methyl phosphonate $4\left(\mathrm{~K}_{\mathrm{I}}\right.$ of 51.7 $\mathrm{nM})$, simple phosphonamidate $\mathbf{1 5}\left(\mathrm{K}_{\mathrm{I}}\right.$ of $\left.41.3 \mathrm{nM}\right)$ and morpholine derivatives $\mathbf{1 9}\left(\mathrm{K}_{\mathrm{I}}\right.$ of $\left.43.9 \mathrm{nM}\right)$ stood out as the best CA VA inhibitors herein, whereas a drop of efficacy was consistently observed with thiophosphonates 12-14 ( $\mathrm{K}_{\mathrm{I}} \mathrm{S}$ of 150.7-641.9 nM). Phosphonamidate 15 was also detected as the most effective inhibitor against $\mathrm{CA} V \mathrm{VB}\left(\mathrm{K}_{\mathrm{I}}\right.$ of $\left.12.6 \mathrm{nM}\right)$ in a comparable manner with bisbenzenesulfonamide $\mathbf{1 0}\left(\mathrm{K}_{\mathrm{I}}\right.$ of $\left.15.0 \mathrm{nM}\right)$. The aliphatic thiophosphonates $\mathbf{1 1}$ and $\mathbf{1 2}$ showed to act as the worst CA VB inhibitors with $\mathrm{K}_{\mathrm{I}} \mathrm{S}$ of 96.7 and $224.6 \mathrm{nM}$. The remaining compounds showed $\mathrm{K}_{\mathrm{I}} \mathrm{S}$ spanning in a rather narrow range between 20 and $60 \mathrm{nM}$.

As CA II, the other target isozyme CA VII was efficiently inhibited by compounds 3-22 as $\mathrm{K}_{\mathrm{I}} \mathrm{S}$ did not raise above $50 \mathrm{nM}$ (spanning from 5.5 to $41.5 \mathrm{nM}$ ), with the exception of thiophosphonates $\mathbf{1 2}$ and $\mathbf{1 3}$ ( $\mathrm{K}_{\mathrm{I}}$ of 100.8 and $\left.75.5 \mathrm{nM}\right)$. The isopropyl (6) and bis-sulfamoyl (10) compounds among phosphonates and pyrrolidine (18) and aniline (22) derivatives among phosphonamidates acted as the most potent CA VII inhibitors with $\mathrm{K}_{\mathrm{I}} \mathrm{s}$ below $10 \mathrm{nM}$.

Though not presenting a Phe residue in position 131, but instead a Val or Ala respectively, the tumorassociated CAs IX and XII were potently inhibited by compounds 3-22. In fact, these isozymes display two of the roomiest active sites among hCAs which enable the accommodation and adjustment of a plethora of chemotypes and moieties from CAIs. Interactions with Phe131 might be indeed substituted by hydrophobic contacts with Val and Ala residues, that summed up with other ligand/target hydrophobic interactions within the binding pocket account for low nanomolar inhibitory effectiveness. It should be stressed, for instance, as the lauryl derivative 12, weak inhibitor against other screened isoforms, showed a $50 \mathrm{nM}$ efficacy against CA IX and XII, owing to a likely favored adaptation within 
their binding sites which show rather extended lipophilic pockets. CA IX and CA XII showed rather flat inhibition profiles with $\mathrm{K}_{\mathrm{I}} \mathrm{s}$ spanning in the ranges 2.6-61.9 and 15.4-58.1 nM.

Interestingly, a subset of derivatives can be selected which showed a preferred inhibition against the target CA II and VII over all other isoforms, particularly CA I , IV and VA: the isopropyl (6), propargyl (7), and bis-sulfamoyl (10) phosphonates and phosphonamidates bearing pyrrolidine (18), Nmethylpiperazine (20) and aniline (22). It is fair to stress that these compounds showed selectivity for CA II and VII above one order of magnitude solely over CA I, IV and VA. In contrast, the selectivity index was lower for CA II and VII over CA VB, IX and XII which are, however, minor off-target isoforms with respect to the ubiquitous CA I.

\section{X-ray crystallography}
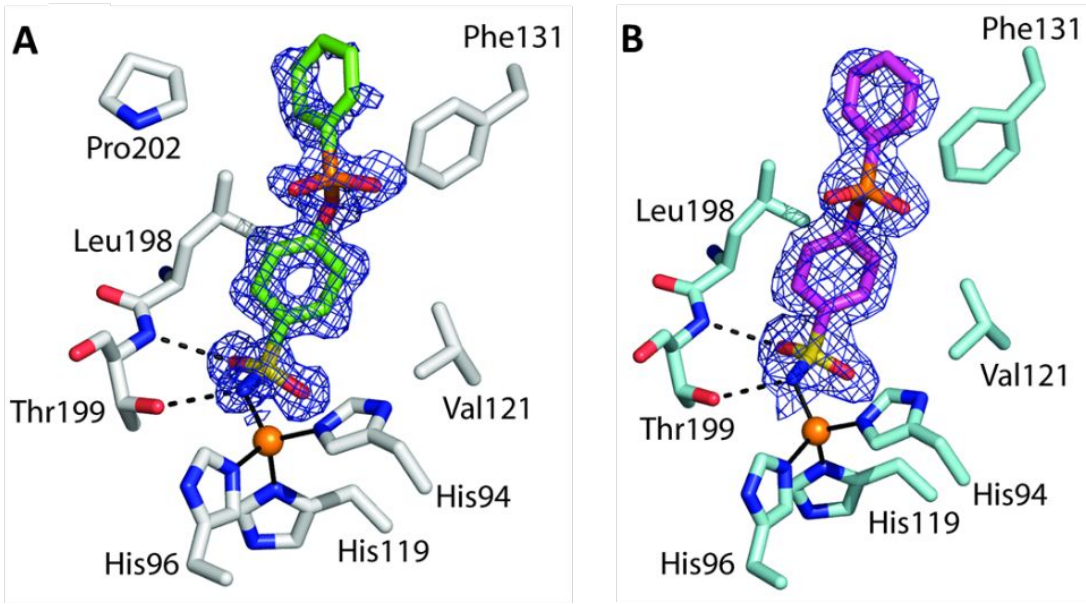

Figure 3. $\sigma \mathrm{A}$-weighted $|2 \mathrm{Fo}-\mathrm{Fc}|$ map (contoured at $1.0 \sigma$ ) relative to the inhibitor molecule in the CA II/3 (A) and CA VII/3 (B) adducts. The zinc ion coordination and residues with a distance less than $4.0 \AA$ from the inhibitor are also reported. Continuous lines show zinc ion coordination, whereas dashed lines indicate potential hydrogen bonds.

In order to understand the molecular basis responsible for the inhibition efficiency of phosphonate/phosphonamidate benzenesulfonamides against CA II and CA VII, the crystal structure of these two isoforms was solved in adduct with phenylphosphonic acid $\mathbf{3}$. This 
compound based on the Chemaxon software ${ }^{36}$ has a pKa value of 1.62 and, therefore, is assumed to bind the enzyme at physiological $\mathrm{pH}$ and in crystallization conditions in a deprotonated, nonchiral form. Crystals of the CAs adducts with $\mathbf{3}$ were obtained by soaking experiments as previously reported for other sulfonamide CA inhibitors. ${ }^{33-35}$ Data were collected to a resolution of $1.26 \AA$ and $1.94 \AA$ for CA II/3 and CA VII/3 complexes, respectively. The structures were analyzed by difference Fourier techniques and refined to Rwork and Rfree values of $14.6 \%$ and $17.4 \%$ for the CA II/ $\mathbf{3}$ complex and $18.8 \%$ and $22.6 \%$ for the CA VII $/ 3$ one (Table S1). Analysis of the electron density maps at various stages of the crystallographic refinement showed in both complexes the binding of one molecule of the inhibitor within the enzyme active site.

The electron density maps were very well defined for both proteins and for the entire inhibitor in the case of CA VII/3. On the contrary, in the case of CA II/3 complex, a less defined electron density was associated to the inhibitor phenyl tail, indicating a higher mobility of this part of the molecule within the CA II active site (Figure 3).
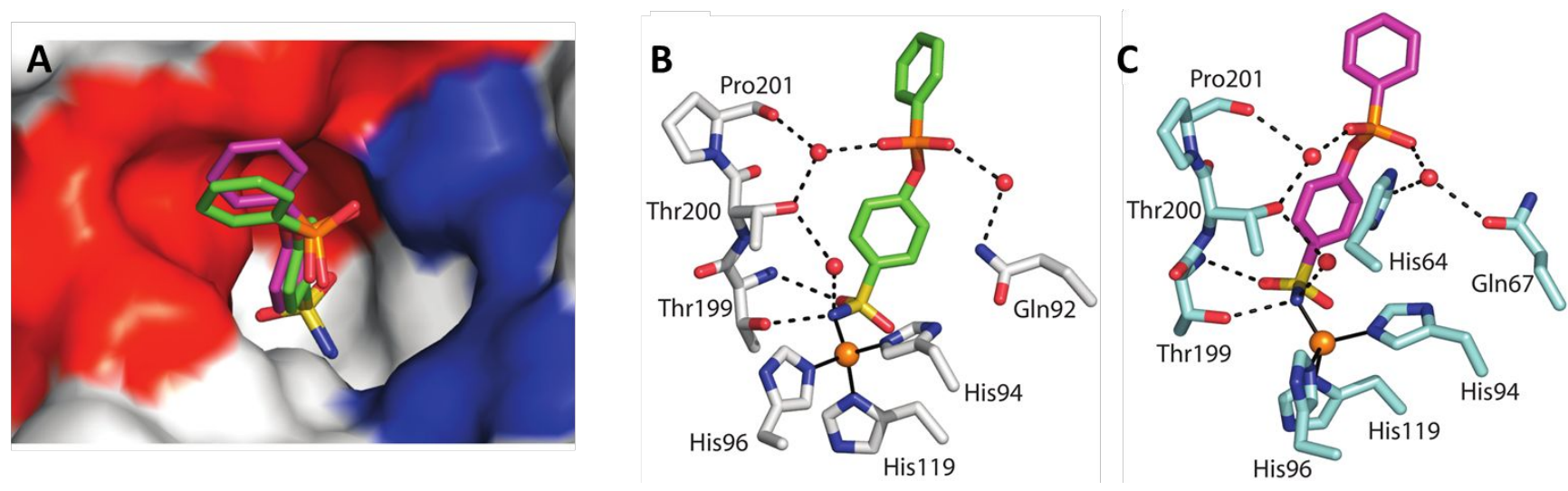

Figure 4. A) Structural superposition of compound 3 when bound to CA II (green) with the same compound when bound to CA VII (magenta). The surface representation of CA II is also shown with hydrophobic region of the active site in red and the hydrophilic one in blue. $(\mathrm{B}, \mathrm{C})$ Details of the polar interactions established by inhibitor 3 within the active site of CA II (B) and CA VII (C). Water molecules are represented as red spheres, continuous lines indicate zinc ion coordination, whereas dashed lines indicate hydrogen bond distances. 
As shown in the structural superposition reported in Figure 4A, the inhibitor adopts the same orientation within the two active sites, with only a small shift of the phenyl tail. In detail, in both structures, the benzenesulfonamide moiety binds the active site in the same conformation adopted in other $\mathrm{CA} /$ benzenesulfonamide complexes, coordinating the catalytic zinc ion, forming two hydrogen bonds with residue Thr199 and establishing many hydrophobic interactions with residues located on the bottom of the cavity (Figure 3 and Table S2). The phosphonate group points toward the hydrophilic region of the active site ${ }^{13}$ and forms in both structures several water mediated hydrogen bonds with enzyme residues (Figures 4B-C). Finally, the phenyl tail is oriented toward the hydrophobic side of the active site ${ }^{13}$ establishing many hydrophobic interactions with residues delimiting this region (Figures 3, 4A and Table S2) and interacting with residue Phe131 as hypothesized in the design. The comparable number and nature of the interactions established by the inhibitor in the two active sites might explain the similarity of the inhibition constants against the two isoforms (Table S2). On the basis of the orientations of the phosphonate oxygens depicted in Figures 3-4, it can be supposed that the substituents included in the P-based linker, both in the $(S)$ - and $(R)$ - enantiomers, are directed towards, and bind the medium and target portion of the CA active site (Figure 2B).

\section{Drug stability study}

The selected subset of compounds $(\mathbf{6}, 7, \mathbf{1 0}, \mathbf{1 8}, \mathbf{2 0}$ and 22) was promoted to in vivo evaluation of their neuropathic pain-relieving action. As the drug administration would have been performed per os, a drug stability study was carried out to verify the endurance of the compounds to different media such as phosphate buffer (PBS), a pH 2 aqueous solution (i.e. $\mathrm{HCl}_{(\mathrm{aq})} 10 \mathrm{mM}$ ) to mimic the stomach environment of the animal, human plasma $(\mathrm{H}-\mathrm{Pl})$ to check the efficiency of hydrolytic enzymes against such phosphonic ester/amide derivatives. The study was performed coupling liquid chromatography to a mass spectrometer working in tandem mass spectrometry mode (LC-MS/MS). 
The collected data indicate that the tested derivatives exhibited stability to all the tested matrices/solutions (Figures S1-S6, Supporting Information), with the exception of derivative $\mathbf{1 8}$ that showed a quick degradation ( $\mathrm{t}_{1 / 2}$ of approximately $2 \mathrm{~min}$ ) in the $\mathrm{pH} 2$ solution (Figure $\mathrm{S} 4$, Supporting Information).

ADMET properties for $\mathbf{6}, \mathbf{7}, \mathbf{1 0}, \mathbf{2 0}, \mathbf{2 2}$ were also predicted by the online server Pre-ADMET ${ }^{37}$ and are reported in Table S4, Supporting Information.

\section{In vivo neuropathic pain-relieving action}

The selected compounds except 18, shown to be unstable in acidic media, were evaluated in vivo for their properties in relieving neuropathic pain induced by the anticancer drug oxaliplatin that is characterized by a relevant neurotoxicity in a high percentage of patients. ${ }^{38}$ This platinum derivative has become a valid option as adjuvant therapy in several types of cancer, but as a common side effect it provokes a painful neuropathy associated with characteristic nervous system alterations that reduce the patients' quality of life. ${ }^{39}$ The pain-relieving effect obtained with the CAIs was compared to that achieved with the reference drugs $\mathbf{A} \mathbf{A Z}$ and duloxetine and the results are showed in Figure 5. Ten oxaliplatin injections decreased the licking latency to $9.0 \pm 0.5 \mathrm{~s}$ in comparison to $18.1 \pm 0.3$ s of the control group (vehicle + vehicle treated animals). Compound $\mathbf{6}$, acutely per os administered in a range doses from $10 \mathrm{mg} \mathrm{kg}^{-1}$ to $100 \mathrm{mg} \mathrm{kg}^{-1}$, evoked a dose dependent anti-neuropathic effect that lasted up to 45 min after treatment with a peak of efficacy at the same time point (Figure 5A). A better anti-neuropathic profile was obtained with compound 7 (Figure 5B), that also showed a dose-dependent antinociceptive effect. The higher dose $\left(100 \mathrm{mg} \mathrm{kg}^{-1}\right)$ was able to totally counteract oxaliplatin-hypersensitivity $30 \mathrm{~min}$ after treatment with a pain-relieving effect that continued up to $45 \mathrm{~min}$. The $30 \mathrm{mg} / \mathrm{kg}$ dose also statistically amplified the pain threshold at $15 \mathrm{~min}$ and $30 \mathrm{~min}$. Likewise, notable results were attained by administration of derivatives $\mathbf{2 0}$ and $\mathbf{2 2}$ as depicted in Figures 5D-E. Compound $\mathbf{1 0}$ evoked a maximum effect $30 \mathrm{~min}$ after administration and uniquely at 
the dose of $100 \mathrm{mg} \mathrm{kg}^{-1}$ (Figure 5C). The reference CAI AAZ was also medium active at the dose of $100 \mathrm{mg} \mathrm{kg}^{-1}$, but solely at 15 min after injection (licking latency of $15.8 \pm 0.7 \mathrm{~s}$ ) (Figure 5F). The weak activity of compound 10, though a strong dual CA II and VII inhibition, can be related to its low water solubility with respect to the other derivatives due to the presence of a double benzenesulfonamide scaffold. Barring 10, derivatives $\mathbf{7}$ and $\mathbf{2 2}$, that totally reverted allodynia in vivo after 30 min post administration, are the most potent CA II inhibitor among the four remaining compounds. The slightly less effective pain-relieving action of 22 respect to 7, although 2-fold more potent as CA VII inhibitor, can be related to its minor water solubility (as predicted in silico, Table S4). In contrast compound $\mathbf{6}, \mathbf{4}$-fold less potent as CA II inhibitor than $\mathbf{7}$ and $\mathbf{2 2}$, but as active as $\mathbf{2 2}$ as CA VII inhibitor, showed a significantly inferior in vivo efficacy. As a result, excluding other participating factors, a greater implication of CA II than CA VII could be speculated. Surprising is the case of the methylpiperazine derivative 20, that is the worst CA II and VII inhibitor among the five compounds but exhibited the quickest in vivo action, reverting the pain sensation after only 15 min. This is likely due to its greater water solubility, which favors its dissolution after per os administration.

The pain-relieving efficacy of the most active derivatives 7, 20 and 22 was comparable (at $30 \mathrm{mg}$ $\mathrm{kg}^{-1}$ ) or even greater (at $100 \mathrm{mg} \mathrm{kg}^{-1}$ ) than that induced by duloxetine (when dosed at $15 \mathrm{mg} \mathrm{kg}^{-1}$, a neuropathic pain relieving dose in animals ${ }^{40}$ (Figure 5F), a standard drug clinically used for the management of chemotherapy-induced neuropathy. ${ }^{41}$ It should be thus stressed that further comparison between the doses of these phosphon(amid)ates and duloxetine cannot be done as such compounds did not share the same mechanism of action. 


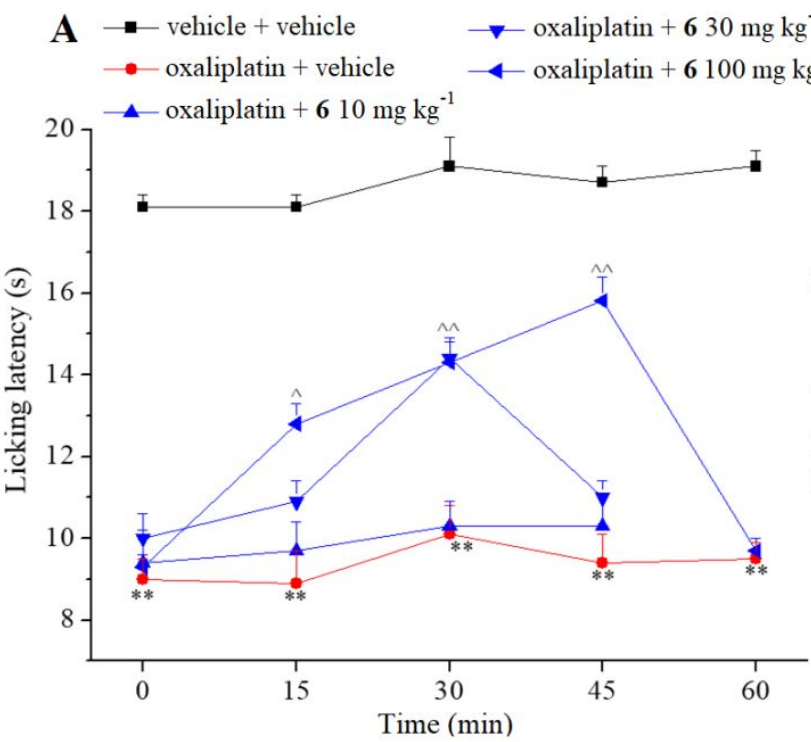

B $\longleftarrow$ oxaliplatin $+710 \mathrm{mg} \mathrm{kg}^{-1} \longleftarrow$ oxaliplatin $+7100 \mathrm{mg} \mathrm{kg}^{-1}$

C $\rightarrow$ oxaliplatin $+\mathbf{1 0} 30 \mathrm{mg} \mathrm{kg}^{-1}$

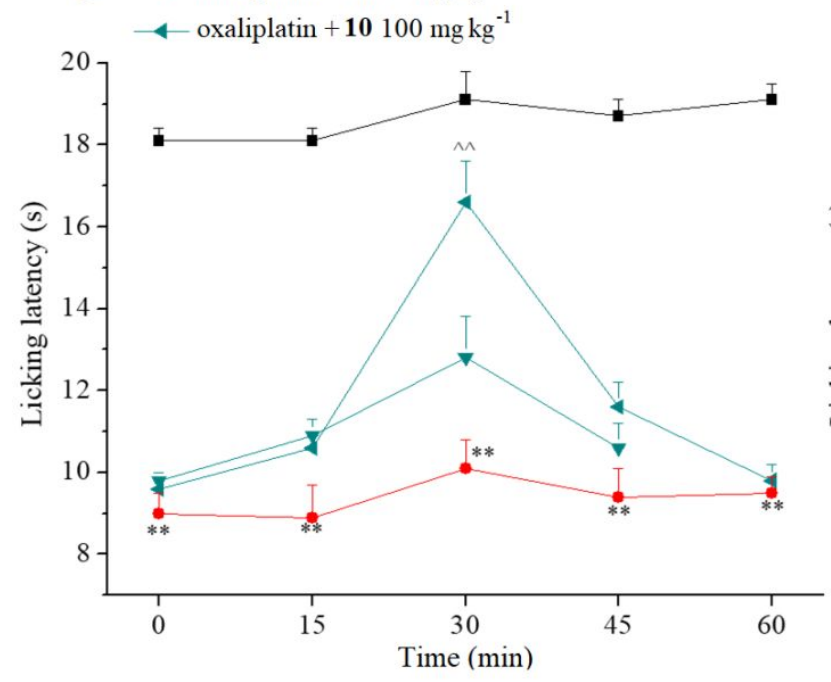

$\checkmark$ - oxaliplatin $+730 \mathrm{mg} \mathrm{kg}^{-1}$

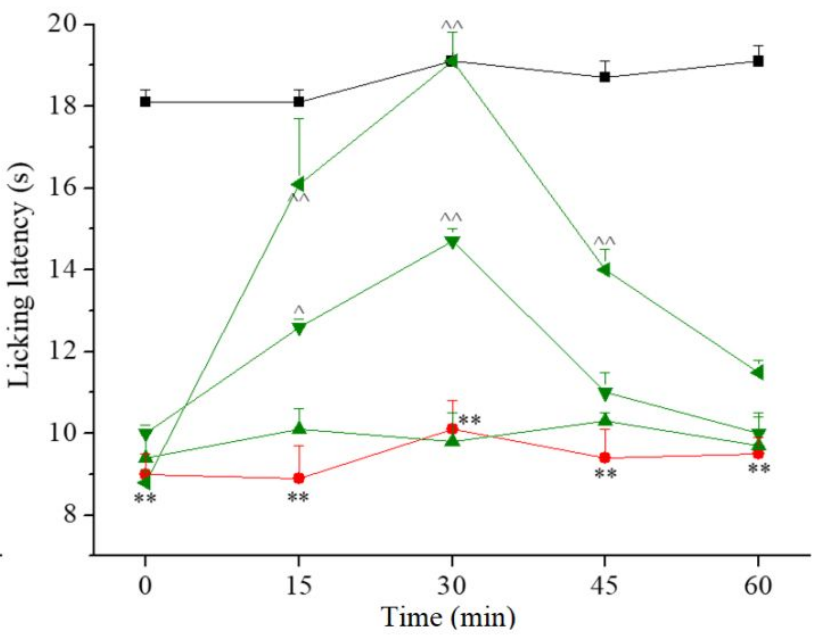

D $\longleftarrow$ oxaliplatin $+\mathbf{2 0} 10 \mathrm{mg} \mathrm{kg}^{-1} \longleftarrow$ oxaliplatin $+\mathbf{2 0} 100 \mathrm{mg} \mathrm{kg}^{-1}$
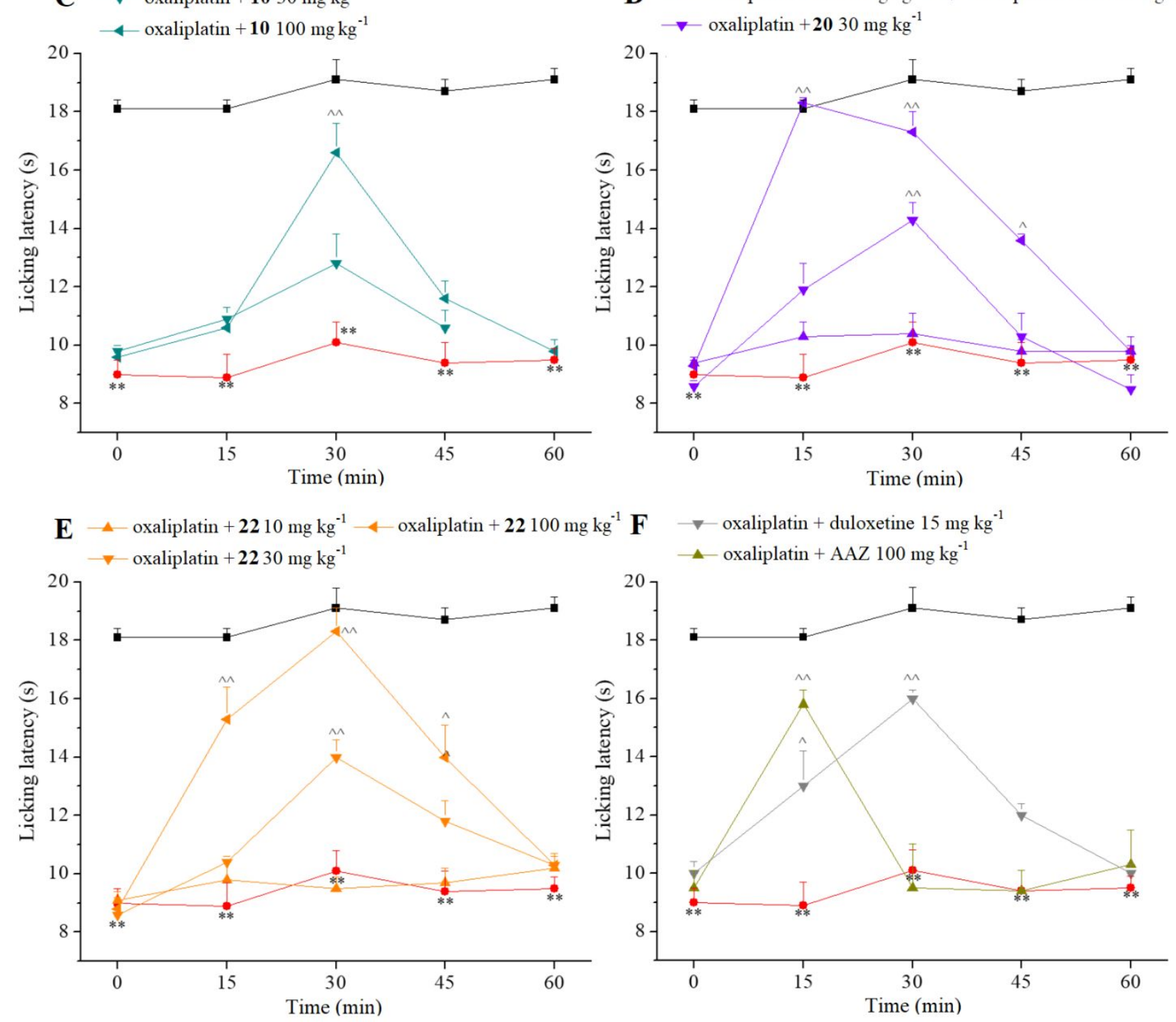
Figure 5. Effect of acute administration of carbonic anhydrase inhibitors 6, 7, 10, 20, 22, $\mathbf{A A Z}$ and duloxetine on oxaliplatin-induced neuropathic pain in the mouse Cold plate test. Oxaliplatin (2.4 $\mathrm{mg} \mathrm{kg}^{-1}$ ) was i.p. administered for 5 consecutive days every week for 2 weeks. Compounds were dissolved in 1\% CMC and per os administered acutely when neuropathy was well established (day 15). Each value represents the mean \pm S.E.M. of 12 mice performed in 2 different experimental sets. Statistical analysis is one-way ANOVA followed by Bonferroni's post-hoc comparison. ${ }^{* *} \mathrm{P}<0.01$ vs vehicle + vehicle treated animals; ${ }^{\wedge} \mathrm{P}<0.05$ and ${ }^{\wedge} \wedge \mathrm{P}<0.01$ vs oxaliplatin + vehicle treated animals.

\section{Chiral resolution and assignment of absolute configuration of compound 7}

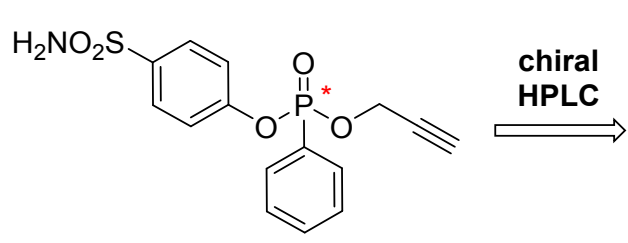

7

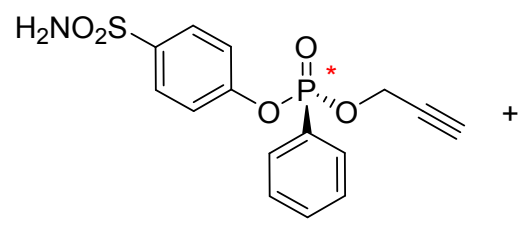

(R)-7

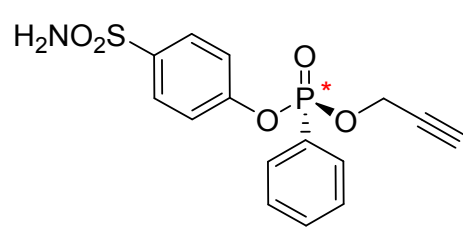

(S)-7

Figure 6. Chiral resolution of compound 7 by chiral HPLC.

The racemic mixture of the most in vivo effective compound, namely compound 7 , was subjected to enantioseparation, accomplished by HPLC on the immobilized-type Chiralpak IA chiral stationary phase under normal phase mode (Figure 6). Both enantiomers could be collected in multi-milligram quantities, by performing repetitive injections of $1 \mathrm{mg}$ of racemic sample on a $250 \mathrm{~mm} \times 10 \mathrm{~mm}$ I.D. Chiralpak IA column. As shown in Figure 7A the 
semipreparative HPLC resolution was achieved in non-overlapping band conditions. The analytical control of the collected fractions gave an enantiomeric excess of both enantiomers higher than $98 \%$.

In order to determine the absolute configuration and then the enantiomer elution order on the chiral chromatographic support, the chiroptical properties (i.e. CD and ORD spectra) of the enantiomers isolated by HPLC were measured and compared with the calculated ones (Figure 7B and C).

A detailed description of the adopted procedure is provided in the Experimental Section.
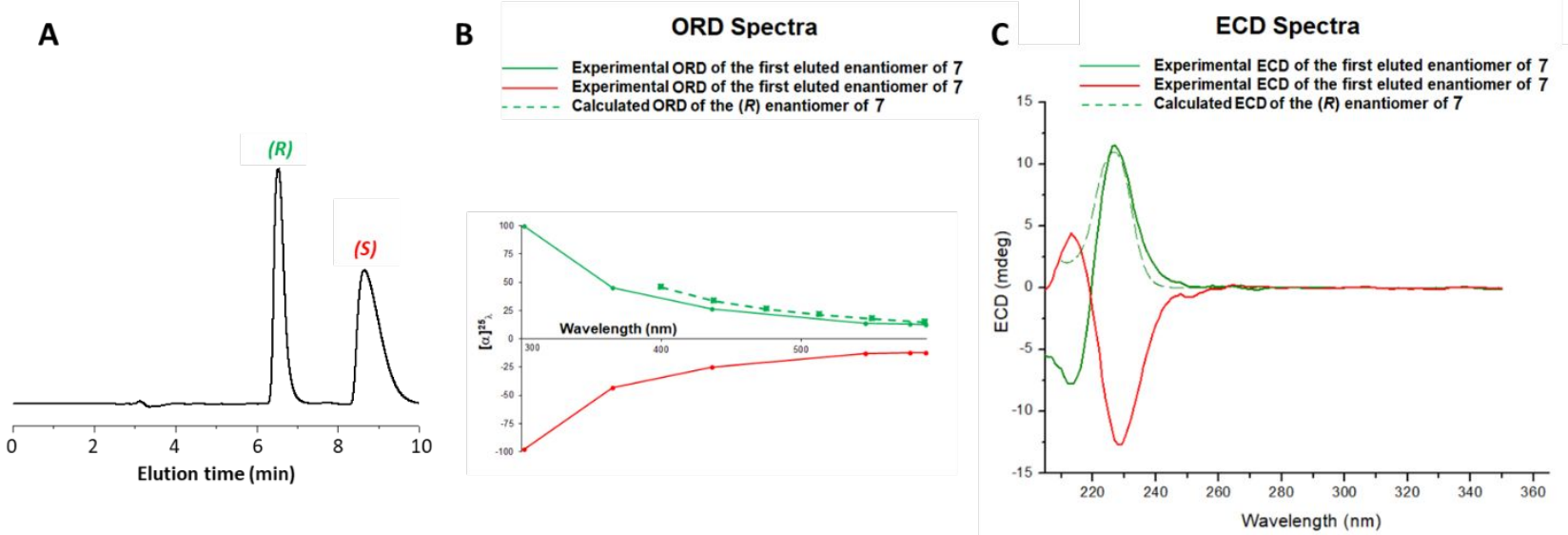

Figure 7. A) Typical chromatogram illustrating the enantioseparation of $1 \mathrm{mg}$ of 7 on the 250 x 10 mm I.D. Chiralpak IA column. Mobile phase: $n$-hexane-EtOH-MeOH-TFA 60:35:5:0.1

(v/v/v/v); flow rate: $4.5 \mathrm{~mL} \mathrm{~min}^{-1}$; temperature: $15^{\circ} \mathrm{C}$; detector: UV at $260 \mathrm{~nm}$. B) ORD and C) ECD spectra of the enantiomers of 7 recorded in ethanol at $25^{\circ} \mathrm{C}$ (solid lines) and 
calculated (dashed lines). Green and red lines refer to the first and second eluted

enantiomers, respectively.

\section{Carbonic anhydrase inhibition of enantiomers of compound 7}

$(R)$ - and $(S)$ - enantiomers of compound 7 were evaluated for their inhibition against the cytosolic CA I, II and VII, the mitochondrial CA VA and VB and the membrane-related CA IV, IX and XII. The following considerations can be made from the data reported in Table 2.

Table 2: Inhibition data of human CA isoforms I, II, IV, VA, VB, VII, IX and XII with compound 7 as racemic mixture and its $(R)$ - and $(S)$ - enantiomers using $\mathbf{A} \mathbf{A Z}$ as standard.

\begin{tabular}{|c|c|c|c|c|c|c|c|c|}
\hline \multirow{2}{*}{ Cmp } & \multicolumn{9}{|c|}{$\mathbf{K}_{\mathbf{I}}(\mathbf{n M})$} \\
\cline { 2 - 9 } & CA I & CA II & CA IV & CA VA & CA VB & CA VII & CA IX & CA XII \\
\hline $\mathbf{7}$ & $415.3 \pm 29.0$ & $3.6 \pm 0.2$ & $1322 \pm 124$ & $82.1 \pm 5.7$ & $38.4 \pm 2.5$ & $12.2 \pm 0.8$ & $22.6 \pm 1.6$ & $26.7 \pm 1.8$ \\
\hline $\boldsymbol{( R})-\mathbf{7}$ & $365.4 \pm 23.4$ & $56.4 \pm 3.8$ & $1984 \pm 153$ & $66.5 \pm 4.6$ & $66.1 \pm 3.5$ & $71.3 \pm 4.5$ & $47.2 \pm 2.8$ & $49.2 \pm 3.2$ \\
\hline$(\boldsymbol{S})-\mathbf{7}$ & $564.1 \pm 42.7$ & $0.78 \pm 0.06$ & $746.5 \pm 38.4$ & $108.3 \pm 8.6$ & $19.2 \pm 1.5$ & $1.1 \pm 0.1$ & $10.5 \pm 1.4$ & $17.3 \pm 1.3$ \\
\hline
\end{tabular}

a. Inhibition data are expressed as means \pm SEM of three different assays.

Enantiomer $(\boldsymbol{S})-\mathbf{7}$ resulted to be the eutomer within the racemic mixture against most screened CA isoforms, that are CA II, IV, VB, VII, IX and XII. Unique exceptions are CA I and VA, against which $(\boldsymbol{R})-7$ showed $\mathrm{K}_{\mathrm{I}} \mathrm{s}$ of 365.4 and $66.5 \mathrm{nM}$ respectively, arising as eutomer. Astonishingly, the CA inhibition profile of (S)-7 was even improved when compared to 7 in terms of potency and selectivity for the target CAs over off-target ones. Indeed, CA II was inhibited at a subnanomolar value of $0.78 \mathrm{nM}$ by $(\boldsymbol{S})-7$, whereas the $\mathrm{K}_{\mathrm{I}}$ against CA VII reached the single-digit value of $1.1 \mathrm{nM}$. Moreover, the $\mathrm{K}_{\mathrm{I}}$ of $(\boldsymbol{S})-\mathbf{7}$ halved against CA VB and CA IX with respect to 7, while an inferior difference was measured between $\mathrm{K}_{\mathrm{I}} \mathrm{S}$ of $(\boldsymbol{S})-\mathbf{7}$ and $\mathbf{7}$ as racemic mixture against CA XII (17.3 and $26.7 \mathrm{nM}$ respectively).

\section{In vivo neuropathic pain-relieving action with $(R)-7$ and (S)-7.}

The in vivo action of the two enantiomers of compound 7 was thus assessed in the same mouse model of neuropathic pain when hyperalgesia was well established (Figure 8). Searching for a dose 
reverting the allodynia and expecting one of them having a greater efficacy than 7 as racemate, a dose of $50 \mathrm{mg} \mathrm{kg}^{-1}$ was used. According to in vitro outcomes, the study identified in (S)-7 the eutomer, since it counteracted oxaliplatin-induced hyperalgesia comparably to 7 , but notably by the half dose. Surprisingly $50 \mathrm{mg} \mathrm{kg}^{-1}(\boldsymbol{R})-7$ was totally ineffective. This might indicate that a CA II and/or VII inhibition of a certain intensity ( $\mathrm{K}_{\mathrm{I}} \mathrm{S}$ of $(\boldsymbol{R})-\mathbf{7}$ against CA II and VII dropped by 15 - and 6-times respectively with respect to 7) is necessary to produce an action which relieves neuropathic pain.

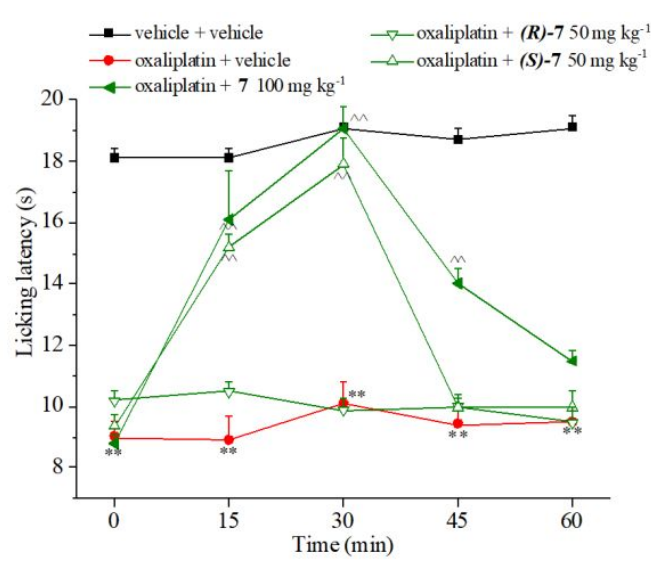

Figure 8. Effect of acute administration of eutomers $(\boldsymbol{R})-\mathbf{7}$ and $(\boldsymbol{S})-\mathbf{7}$, in comparison with $\mathbf{7}$ on oxaliplatin-induced neuropathic pain in the mouse Cold plate test. Oxaliplatin $\left(2.4 \mathrm{mg} \mathrm{kg}^{-1}\right)$ was i.p. administered for 5 consecutive days every week for 2 weeks. Compounds were dissolved in CMC $1 \%$ and per os administered acutely when neuropathy was well established (day 15). Each value represents the mean \pm S.E.M. of 12 mice performed in 2 different experimental sets. Statistical analysis is one-way ANOVA followed by Bonferroni's post-hoc comparison. $* * \mathrm{P}<0.01$ vs vehicle + vehicle treated animals; ${ }^{\wedge} \mathrm{P}<0.05$ and ${ }^{\wedge} \wedge \mathrm{P}<0.01$ vs oxaliplatin + vehicle treated animals.

\section{Conclusions}

NP is induced by ailments or lesion existing in the CNS which produce the sensation of pain in the brain. New promising drug classes are necessary because of difficulties met in treating NP in a vast majority of patients. The human CA isoforms II and VII are implicated in neuronal excitation, seizures and NP. Therefore, their selective inhibition over off-target CAs is expected to produce an anti-NP 
action devoid of side effects, that arise by promiscuous CA inhibition. In this study, a drug-design strategy was planned to produce selective CA II and VII inhibitors. Benzenesulfonamide derivatives with a phosphorus-based linker were adopted for the first time with the aim of pursuing the tail approach for the exploration of the middle portion of the CA active site cavity. A subset of potent and selective CA II/VII inhibitors was identified among the synthesized phenyl(thio)phosphon(amid)ates 3-22. It is fair to stress that these compounds showed selectivity for CA II and VII above one order of magnitude solely over CA I, IV and VA. In contrast, the selectivity index was lower for CA II and VII over CA VB, IX and XII which are, however, minor off-target isoforms with respect to the ubiquitous CA I.

The efficacy of the adopted drug-design strategy was confirmed at the molecular level by X-ray crystallographic studies depicting the binding mode of phosphonic acid $\mathbf{3}$ to both CA II and VII. The most promising derivatives for potent and preferred inhibition against the target CA II and VII over all other isoforms, after evaluation for their stability in acidic media, were tested in a mouse model of oxaliplatin-induced neuropathy. The most potent compound (7) racemic mixture was also subjected to semipreparative HPLC resolution and the identification of eutomer for CA II and VII inhibition (S)-7 even allowed to halve the dose totally reverting allodynia in mice from 100 to 50 $\mathrm{mg} / \mathrm{kg}$.

These results testify the efficacy of the adopted drug-design strategy towards CA II/VII inhibitors for the treatment of NP and overall support the potentiality of (thio)phosphon(amid)ate linker for yielding potent and selective CA inhibitors for therapeutic applications.

\section{Experimental Section}

\section{Chemistry}

Anhydrous solvents and all reagents were purchased from Sigma-Aldrich, Fluorochem and TCI. All reactions involving air- or moisture-sensitive compounds were performed under a nitrogen atmosphere using dried glassware and syringes techniques to transfer solutions. Nuclear magnetic 
resonance $\left({ }^{1} \mathrm{H}-\mathrm{NMR},{ }^{13} \mathrm{C}-\mathrm{NMR},{ }^{31} \mathrm{P}-\mathrm{NMR}\right)$ spectra were recorded using a Bruker Advance III 400 $\mathrm{MHz}$ spectrometer in DMSO- $\mathrm{d}_{6}$. Chemical shifts are reported in parts per million (ppm) and the coupling constants $(J)$ are expressed in Hertz $(\mathrm{Hz})$. Splitting patterns are designated as follows: s, singlet; d, doublet; sept, septet; t, triplet; q, quadruplet; m, multiplet; bs, broad singlet; dd, double of doublets. The assignment of exchangeable protons $(\mathrm{OH}$ and $\mathrm{N} H)$ was confirmed by the addition of $\mathrm{D}_{2} \mathrm{O}$. Analytical thin-layer chromatography (TLC) was carried out on Sigma Aldrich silica gel F-254 plates. Flash chromatography purifications were performed on Sigma Aldrich Silica gel 60 (230-400 mesh ASTM) as the stationary phase and ethyl acetate/n-hexane or $\mathrm{MeOH} / \mathrm{DCM}$ were used as eluents. Melting points (mp) were measured in open capillary tubes with a Gallenkamp MPD350.BM3.5 apparatus and are uncorrected.

Compounds 3-22 were $\geq 95 \%$ pure. The purity of the final compounds was determined by an Agilent 1200 liquid chromatography system composed by autosampler, binary pumps, column oven and diode-array detector (LC-DAD) operating in UV range (210-400 nm). The operating conditions are reported in the Supporting Information. The following chromatographic parameters were employed to check the purity of the compounds: (i) column, Luna PFP length $=50 \mathrm{~mm}$, internal diameter $=$ $2 \mathrm{~mm}$; particle size $=3 \mu \mathrm{m}$ purchased from Phenomenex (Bologna, Italy); (ii) the eluents used were $10 \mathrm{mM}$ formic acid and $5 \mathrm{mM}$ ammonium formate in water solution (solvent $\mathrm{A}$ ) and $10 \mathrm{mM}$ ammonium formate and $5 \mathrm{mM}$ formic acid in methanol (solvent $\mathrm{B}$ ); (iii) flow rate and the injection volume were $0.25 \mathrm{~mL} \mathrm{m^{-1 }}$ and $5 \mu \mathrm{L}$, respectively. The elution gradient is shown in Table S3, Supporting Information. The HPLC-chromatograms are depicted in Figures S7-27, Supporting Information.

The high-resolution mass spectrometry (HRMS) analysis were performed with a Thermo Finnigan LTQ Orbitrap mass spectrometer equipped with an electrospray ionization source (ESI). The analysis were carried out introducing, via syringe pump at $10 \mu \mathrm{L} \mathrm{min}-1$, the sample solution $(1.0 \mu \mathrm{g} \mathrm{mL}-1$ in $\mathrm{mQ}$ water:acetonitrile 50:50), and it was acquired the signal of the positive ions. These experimental 
conditions allow the monitoring of protonated molecules of the studied compounds $\left([\mathrm{M}+\mathrm{H}]^{+}\right.$species $)$, that were measured with a proper dwell time to achieve 60,000 units of resolution at Full Width at Half Maximum (FWHM). Elemental compositions of compounds were calculated on the basis of their measured accurate masses, accepting only results with an attribution error less than $2.5 \mathrm{ppm}$ and a not integer RDB (double bond/ring equivalents) value, in order to consider only the protonated species. $^{42}$

\section{General synthetic procedure of compounds (3-22).}

Phenylphosphonic dichloride 2 (1.2 eq) was quickly added to a solution of 4hydroxybenzenesulfonamide $1(0.3 \mathrm{~g}, 1.0 \mathrm{eq})$ and trimethylamine $(2.2 \mathrm{eq})$ in dry $\mathrm{THF}(10 \mathrm{ml})$ at $-5^{\circ} \mathrm{C}$ under a nitrogen atmosphere and the resulting suspension was stirred for $0.5 \mathrm{~h}$ at $0^{\circ} \mathrm{C}$. The proper reactant was added to the mixture and that was stirred at r.t. for $1 \mathrm{~h}$. The reaction mixture was concentrated in vacuo and the obtained residue purified by silica gel coloumn chromatography eluting with $\mathrm{MeOH} / \mathrm{DCM}$ to afford the title compounds 3-23 as powders.

\section{4-Sulfamoylphenyl hydrogen phenylphosphonate (3).}

Compound 3 was obtained according the general procedure earlier reported using $\mathrm{H}_{2} \mathrm{O}(5.0$ eq), phenylphosphonic dichloride 2 (1.2 eq), 4-hydroxybenzenesulfonamide 1 (0.3 g, 1.0 eq) and trimethylamine $(2.2 \mathrm{eq})$ in dry THF $(10 \mathrm{ml})$. The reaction mixture was concentrated in vacuo and the obtained residue purified by silica gel coloumn chromatography eluting with $4 \% \mathrm{MeOH}$ in DCM to afford the title compound as white solid. $55 \%$ yield; m.p. $183-184^{\circ} \mathrm{C}$; silica gel TLC $R_{f} 0.11$ $\left(\mathrm{MeOH} / \mathrm{CH}_{2} \mathrm{Cl}_{2} 15 \% \mathrm{v} / \mathrm{v}\right) ; \delta_{\mathrm{H}}\left(400 \mathrm{MHz}, \mathrm{DMSO}-d_{6}\right): 7.32\left(\mathrm{~m}, 4 \mathrm{H}\right.$, partial exchange with $\mathrm{D}_{2} \mathrm{O}$, Ar$\left.H+\mathrm{SO}_{2} \mathrm{NH}_{2}\right), 7.55(\mathrm{~m}, 2 \mathrm{H}, \mathrm{Ar}-H), 7.63(\mathrm{~m}, 1 \mathrm{H}, \mathrm{Ar}-H), 7.87(\mathrm{~m}, 4 \mathrm{H}, \mathrm{Ar}-H) ; \delta_{\mathrm{C}}(100 \mathrm{MHz}, \mathrm{DMSO}-$ $\left.d_{6}\right): 121.56\left(\mathrm{~d}, J^{3}{ }_{\mathrm{CP}}=4.9\right), 128.50,129.48\left(\mathrm{~d}, J^{2}{ }_{\mathrm{CP}}=14.7\right), 131.05\left(\mathrm{~d}, J^{1}{ }_{\mathrm{CP}}=185.8\right), 132.21\left(\mathrm{~d}, J^{3}{ }_{\mathrm{CP}}\right.$ 
$=9.9), 133.16\left(\mathrm{~d}, J^{4}{ }_{\mathrm{CP}}=3.2\right), 140.77,154.27\left(\mathrm{~d}, J^{2}{ }_{\mathrm{CP}}=6.6\right) ; \delta_{\mathrm{P}}\left(162 \mathrm{MHz}, \mathrm{DMSO}-d_{6}\right) 12.01$; ESIHRMS (m/z) $[\mathrm{M}+\mathrm{H}]^{+}$: calculated for C12H13NO5PS 314.0252; found 314.0247.

\section{Methyl (4-sulfamoylphenyl) phenylphosphonate (4).}

Compound 4 was obtained according the general procedure earlier reported using $\mathrm{MeOH}$ (5.0 eq), phenylphosphonic dichloride 2 (1.2 eq), 4-hydroxybenzenesulfonamide $\mathbf{1}(0.3 \mathrm{~g}, 1.0 \mathrm{eq})$ and trimethylamine $(2.2 \mathrm{eq})$ in dry THF $(10 \mathrm{ml})$. The reaction mixture was concentrated in vacuo and the obtained residue purified by silica gel coloumn chromatography eluting with $4 \% \mathrm{MeOH}$ in DCM to afford the title compound as white waxy solid. $28 \%$ yield; m.p. $92-93^{\circ} \mathrm{C}$; silica gel TLC $R_{f} 0.31$ $\left(\mathrm{MeOH} / \mathrm{CH}_{2} \mathrm{Cl}_{2} 5 \% \mathrm{v} / \mathrm{v}\right) ; \delta_{\mathrm{H}}\left(400 \mathrm{MHz}, \mathrm{DMSO}-d_{6}\right): 3.87\left(\mathrm{~d}, J=11.4,3 \mathrm{H}, \mathrm{OCH}_{3}\right), 7.38(\mathrm{~s}, 2 \mathrm{H}$, exchange with $\left.\mathrm{D}_{2} \mathrm{O}, \mathrm{SO}_{2} \mathrm{NH}_{2}\right), 7.41(\mathrm{~m}, 2 \mathrm{H}, \mathrm{Ar}-H), 7.64(\mathrm{~m}, 2 \mathrm{H}, \mathrm{Ar}-H), 7.75(\mathrm{~m}, 1 \mathrm{H}, \operatorname{Ar}-H), 7.81$ $(\mathrm{m}, 4 \mathrm{H}, \mathrm{Ar}-H) ; \delta_{\mathrm{C}}\left(100 \mathrm{MHz}, \mathrm{DMSO}-d_{6}\right): 54.29\left(\mathrm{~d}, J^{2}{ }_{\mathrm{CP}}=6.0\right), 121.64\left(\mathrm{~d}, J^{3}{ }_{\mathrm{CP}}=4.4\right), 126.95(\mathrm{~d}, J$ $\left.{ }^{1} \mathrm{CP}=187.8\right), 128.74,129.95\left(\mathrm{~d}, J^{2}{ }_{\mathrm{CP}}=15.2\right), 132.63\left(\mathrm{~d}, J^{3}{ }_{\mathrm{CP}}=10.4\right), 134.39\left(\mathrm{~d}, J^{4}{ }_{\mathrm{CP}}=3.1\right), 141.61$, $153.29\left(\mathrm{~d}, J^{2}{ }_{\mathrm{CP}}=6.6\right) ; \delta_{\mathrm{P}}\left(162 \mathrm{MHz}, \mathrm{DMSO}-d_{6}\right) 16.73$; ESI-HRMS $(\mathrm{m} / \mathrm{z})[\mathrm{M}+\mathrm{H}]^{+}:$calculated for C13H15NO5PS 328.0408; found 328.0402.

\section{Ethyl (4-sulfamoylphenyl) phenylphosphonate (5).}

Compound 5 was obtained according the general procedure earlier reported using EtOH (5.0 eq), phenylphosphonic dichloride 2 (1.2 eq), 4-hydroxybenzenesulfonamide 1 (0.3 g, $1.0 \mathrm{eq})$ and trimethylamine $(2.2 \mathrm{eq})$ in dry THF $(10 \mathrm{ml})$. The reaction mixture was concentrated in vacuo and the obtained residue purified by silica gel coloumn chromatography eluting with $4 \% \mathrm{MeOH}$ in $\mathrm{DCM}$ to afford the title compound as white waxy solid. 33 yield; m.p. $98-99^{\circ} \mathrm{C}$; silica gel TLC $R_{f} 0.52$ $\left(\mathrm{MeOH} / \mathrm{CH}_{2} \mathrm{Cl}_{2} 10 \% \mathrm{v} / \mathrm{v}\right) ; \delta_{\mathrm{H}}\left(400 \mathrm{MHz}, \mathrm{DMSO}-d_{6}\right): 1.32\left(\mathrm{t}, J=7.0,3 \mathrm{H}, \mathrm{CH}_{2} \mathrm{CH}_{3}\right), 4.25(\mathrm{~m}, 2 \mathrm{H}$, $\left.\mathrm{OCH}_{2}\right), 7.38\left(\mathrm{~s}, 2 \mathrm{H}\right.$, exchange with $\left.\mathrm{D}_{2} \mathrm{O}, \mathrm{SO}_{2} \mathrm{~N} H_{2}\right), 7.40(\mathrm{~m}, 2 \mathrm{H}, \mathrm{Ar}-H), 7.62(\mathrm{~m}, 2 \mathrm{H}, \mathrm{Ar}-H), 7.73(\mathrm{~m}$, $1 \mathrm{H}, \operatorname{Ar}-H), 7.86(\mathrm{~m}, 4 \mathrm{H}, \mathrm{Ar}-H) ; \delta_{\mathrm{C}}\left(100 \mathrm{MHz}, \mathrm{DMSO}-d_{6}\right): 17.05\left(\mathrm{~d}, J^{3}{ }_{\mathrm{CP}}=6.1\right), 64.01\left(\mathrm{~d}, J^{2}{ }_{\mathrm{CP}}=\right.$ 
5.9), $121.71\left(\mathrm{~d}, J^{3}{ }_{\mathrm{CP}}=4.8\right), 127.65\left(\mathrm{~d}, J^{1}{ }_{\mathrm{CP}}=188.6\right), 128.77,129.97\left(\mathrm{~d}, J^{2}{ }_{\mathrm{CP}}=15.3\right), 132.59(\mathrm{~d}, J$ $\left.{ }^{3}{ }_{\mathrm{CP}}=10.3\right), 134.33\left(\mathrm{~d}, J^{4}{ }_{\mathrm{CP}}=3.2\right), 141.55,153.40\left(\mathrm{~d}, J^{2}{ }_{\mathrm{CP}}=6.7\right) ; \delta_{\mathrm{P}}\left(162 \mathrm{MHz}, \mathrm{DMSO}-d_{6}\right) 15.36 ;$ ESI-HRMS (m/z) [M+H] $]^{+}$: calculated for C14H17NO5PS 342.0565; found 342.0560.

\section{Isopropyl (4-sulfamoylphenyl) phenylphosphonate (6).}

Compound 6 was obtained according the general procedure earlier reported using iPrOH (5.0 eq), phenylphosphonic dichloride 2 (1.2 eq), 4-hydroxybenzenesulfonamide 1 (0.3 g, $1.0 \mathrm{eq})$ and trimethylamine $(2.2 \mathrm{eq})$ in dry THF $(10 \mathrm{ml})$. The reaction mixture was concentrated in vacuo and the obtained residue purified by silica gel coloumn chromatography eluting with $4 \% \mathrm{MeOH}$ in $\mathrm{DCM}$ to afford the title compound as white solid. $44 \%$ yield; m.p. $106-107^{\circ} \mathrm{C}$; silica gel TLC $R_{f} 0.45$ $\left(\mathrm{MeOH} / \mathrm{CH}_{2} \mathrm{Cl}_{2} 10 \% \mathrm{v} / \mathrm{v}\right) ; \delta_{\mathrm{H}}\left(400 \mathrm{MHz}, \mathrm{DMSO}-d_{6}\right): 1.33\left(\mathrm{dd}, J=6.2,22.4,6 \mathrm{H}, \mathrm{CH}\left(\mathrm{CH}_{3}\right)_{2}\right), 4.83$ (m, $1 \mathrm{H}, \mathrm{OCH}), 7.37\left(\mathrm{~s}, 2 \mathrm{H}\right.$, exchange with $\mathrm{D}_{2} \mathrm{O}, \mathrm{SO}_{2} \mathrm{NH}_{2}$, overlap with signal at 7.39), $7.39(\mathrm{~m}, 2 \mathrm{H}$, Ar- $H), 7.62(\mathrm{~m}, 2 \mathrm{H}, \mathrm{Ar}-H), 7.72(\mathrm{~m}, 1 \mathrm{H}, \mathrm{Ar}-H), 7.86(\mathrm{~m}, 4 \mathrm{H}, \mathrm{Ar}-H) ; \delta_{\mathrm{C}}\left(100 \mathrm{MHz}, \mathrm{DMSO}-d_{6}\right): 24.43$ $\left(\mathrm{d}, J^{3}{ }_{\mathrm{CP}}=7.3\right), 73.07\left(\mathrm{~d}, J^{2}{ }_{\mathrm{CP}}=6.0\right), 121.71\left(\mathrm{~d}, J^{3}{ }_{\mathrm{CP}}=4.8\right), 128.36\left(\mathrm{~d}, J^{1}{ }_{\mathrm{CP}}=188.2\right), 128.64,129.81$ $\left(\mathrm{d}, J^{2}{ }_{\mathrm{CP}}=15.3\right), 132.43\left(\mathrm{~d}, J^{3}{ }_{\mathrm{CP}}=10.3\right), 134.08\left(\mathrm{~d}, J^{4}{ }_{\mathrm{CP}}=3.0\right), 141.43,153.42\left(\mathrm{~d}, J^{2}{ }_{\mathrm{CP}}=6.7\right) ; \delta_{\mathrm{P}}$ (162 MHz, DMSO- $\left.d_{6}\right)$ 14.31; ESI-HRMS $(\mathrm{m} / \mathrm{z})[\mathrm{M}+\mathrm{H}]^{+}$: calculated for C15H19NO5PS 356.0721; found 356.0716 .

\section{Propargyl (4-sulfamoylphenyl) phenylphosphonate (7).}

Compound 7 was obtained according the general procedure earlier reported using propargyl alcohol (5.0 eq), phenylphosphonic dichloride $\mathbf{2}$ (1.2 eq), 4-hydroxybenzenesulfonamide $\mathbf{1}$ ( $0.3 \mathrm{~g}, 1.0 \mathrm{eq})$ and trimethylamine $(2.2 \mathrm{eq})$ in dry THF $(10 \mathrm{ml})$. The reaction mixture was concentrated in vacuo and the obtained residue purified by silica gel coloumn chromatography eluting with $4 \% \mathrm{MeOH}$ in $\mathrm{DCM}$ to afford the title compound as white solid. $51 \%$ yield; m.p. $165-166^{\circ} \mathrm{C}$; silica gel TLC $R_{f} 0.28$ $\left(\mathrm{MeOH} / \mathrm{CH}_{2} \mathrm{Cl}_{2} 5 \% \mathrm{v} / \mathrm{v}\right) ; \delta_{\mathrm{H}}\left(400 \mathrm{MHz}, \mathrm{DMSO}-d_{6}\right): 3.74\left(\mathrm{t}, J=2.4,1 \mathrm{H}, \mathrm{CH}_{2} \mathrm{CH}\right), 4.94(\mathrm{~m}, 2 \mathrm{H}$, 
$\left.\mathrm{OCH}_{2}\right), 7.39\left(\mathrm{~s}, 2 \mathrm{H}\right.$, exchange with $\left.\mathrm{D}_{2} \mathrm{O}, \mathrm{SO}_{2} \mathrm{~N} H_{2}\right), 7.42(\mathrm{~m}, 2 \mathrm{H}, \mathrm{Ar}-H), 7.64(\mathrm{~m}, 2 \mathrm{H}, \mathrm{Ar}-\mathrm{H}), 7.75(\mathrm{~m}$, $1 \mathrm{H}, \operatorname{Ar}-H), 7.89(\mathrm{~m}, 4 \mathrm{H}, \operatorname{Ar}-H) ; \delta_{\mathrm{C}}\left(100 \mathrm{MHz}, \mathrm{DMSO}-d_{6}\right): 55.30\left(\mathrm{~d}, J^{3}{ }_{\mathrm{CP}}=6.0\right), 78.89\left(\mathrm{~d}, J^{2}{ }_{\mathrm{CP}}=\right.$ 6.6), 79.99, $121.65\left(\mathrm{~d}, J^{3}{ }_{\mathrm{CP}}=4.4\right), 127.06\left(\mathrm{~d}, J^{1}{ }_{\mathrm{CP}}=190.03\right), 128.68,129.87\left(\mathrm{~d}, J^{2}{ }_{\mathrm{CP}}=15.5\right), 132.53$ $\left(\mathrm{d}, J^{3}{ }_{\mathrm{CP}}=10.7\right), 134.46\left(\mathrm{~d}, J^{4}{ }_{\mathrm{CP}}=3.2\right), 141.71,153.06\left(\mathrm{~d}, J^{2}{ }_{\mathrm{CP}}=7.3\right) ; \delta_{\mathrm{P}}\left(162 \mathrm{MHz}, \mathrm{DMSO}-d_{6}\right)$ 16.32; ESI-HRMS (m/z) [M+H] $]^{+}$: calculated for C15H15NO5PS 352.0408; found 352.0402.

\section{2-Methoxyethyl (4-sulfamoylphenyl) phenylphosphonate (8).}

Compound $\mathbf{8}$ was obtained according the general procedure earlier reported using 2-methoxyethanol (5.0 eq), phenylphosphonic dichloride 2 (1.2 eq), 4-hydroxybenzenesulfonamide $\mathbf{1}(0.3 \mathrm{~g}, 1.0 \mathrm{eq})$ and trimethylamine $(2.2 \mathrm{eq})$ in dry THF $(10 \mathrm{ml})$. The reaction mixture was concentrated in vacuo and the obtained residue purified by silica gel coloumn chromatography eluting with $4 \% \mathrm{MeOH}$ in DCM to afford the title compound as white solid. 61 yield; m.p. $102-103^{\circ} \mathrm{C}$; silica gel TLC $R_{f} 0.47$ $\left(\mathrm{MeOH} / \mathrm{CH}_{2} \mathrm{Cl}_{2} 20 \% \mathrm{v} / \mathrm{v}\right) ; \delta_{\mathrm{H}}\left(400 \mathrm{MHz}, \mathrm{DMSO}-d_{6}\right): 3.25\left(\mathrm{~s}, 3 \mathrm{H}, \mathrm{OCH}_{3}\right), 3.58\left(\mathrm{~m}, 2 \mathrm{H}, \mathrm{CH}_{2}\right), 4.29$ (m, 2H, $\left.\mathrm{CH}_{2}\right), 7.37$ (s, 2H, exchange with $\left.\mathrm{D}_{2} \mathrm{O}, \mathrm{SO}_{2} \mathrm{NH}_{2}\right), 7.41(\mathrm{~m}, 2 \mathrm{H}, \mathrm{Ar}-H), 7.63(\mathrm{~m}, 2 \mathrm{H}, \mathrm{Ar}-H)$, $7.73(\mathrm{~m}, 1 \mathrm{H}, \operatorname{Ar}-H), 7.87(\mathrm{~m}, 4 \mathrm{H}, \operatorname{Ar}-H) ; \delta_{\mathrm{C}}\left(100 \mathrm{MHz}, \mathrm{DMSO}-d_{6}\right): 58.82,66.62\left(\mathrm{~d}, J^{3}{ }_{\mathrm{CP}}=5.9\right)$, $71.56\left(\mathrm{~d}, J^{2}{ }_{\mathrm{CP}}=6.5\right), 121.60\left(\mathrm{~d}, J^{3}{ }_{\mathrm{CP}}=4.5\right), 127.55\left(\mathrm{~d}, J^{1}{ }_{\mathrm{CP}}=190.1\right), 128.64,129.80\left(\mathrm{~d}, J^{2}{ }_{\mathrm{CP}}=15.2\right)$, $132.49\left(\mathrm{~d}, J^{3}{ }_{\mathrm{CP}}=10.3\right), 134.20\left(\mathrm{~d}, J^{4}{ }_{\mathrm{CP}}=3.0\right), 141.54,153.29\left(\mathrm{~d}, J^{2}{ }_{\mathrm{CP}}=7.2\right) ; \delta_{\mathrm{P}}(162 \mathrm{MHz}, \mathrm{DMSO}-$ $\left.d_{6}\right)$ 15.67; ESI-HRMS (m/z) [M+H] $]^{+}$: calculated for C15H16NO6PS 369.0436; found 369.0431.

\section{Phenyl (4-sulfamoylphenyl) phenylphosphonate (9).}

ompound 9 was obtained according the general procedure earlier reported using phenol (2.0 eq), phenylphosphonic dichloride 2 (1.2 eq), 4-hydroxybenzenesulfonamide $\mathbf{1}(0.3 \mathrm{~g}, 1.0 \mathrm{eq})$ and trimethylamine $(2.2 \mathrm{eq})$ in dry THF $(10 \mathrm{ml})$. The reaction mixture was concentrated in vacuo and the obtained residue purified by silica gel coloumn chromatography eluting with $4 \% \mathrm{MeOH}$ in $\mathrm{DCM}$ to afford the title compound as white solid. 53 yield; m.p. $111-112^{\circ} \mathrm{C}$; silica gel TLC $R_{f} 0.51$ 
$\left(\mathrm{MeOH} / \mathrm{CH}_{2} \mathrm{Cl}_{2} 10 \% \mathrm{v} / \mathrm{v}\right) ; \delta_{\mathrm{H}}\left(400 \mathrm{MHz}, \mathrm{DMSO}-d_{6}\right): 7.25(\mathrm{~m}, 2 \mathrm{H}, \mathrm{Ar}-H), 7.27(\mathrm{~m}, 3 \mathrm{H}, \mathrm{Ar}-H), 7.41$ (s, 2H, exchange with $\left.\mathrm{D}_{2} \mathrm{O}, \mathrm{SO}_{2} \mathrm{NH}_{2}\right), 7.45(\mathrm{~m}, 2 \mathrm{H}, \mathrm{Ar}-H), 7.65(\mathrm{~m}, 2 \mathrm{H}, \mathrm{Ar}-H), 7.78(\mathrm{~m}, 1 \mathrm{H}, \mathrm{Ar}-H)$, $7.88(\mathrm{~m}, 2 \mathrm{H}, \mathrm{Ar}-H), 8.00(\mathrm{~m}, 2 \mathrm{H}, \mathrm{Ar}-H) ; \delta_{\mathrm{C}}\left(100 \mathrm{MHz}, \mathrm{DMSO}-d_{6}\right): 121.64\left(\mathrm{~d}, J^{3}{ }_{\mathrm{CP}}=4.4\right), 121.72$ $\left(\mathrm{d}, J^{3}{ }_{\mathrm{CP}}=4.6\right), 126.41,126.43\left(\mathrm{~d}, J^{1}{ }_{\mathrm{CP}}=190.0\right), 128.86,130.07\left(\mathrm{~d}, J^{2}{ }_{\mathrm{CP}}=15.5\right), 130.97,132.98(\mathrm{~d}$, $\left.J^{3}{ }_{\mathrm{CP}}=10.8\right), 134.87\left(\mathrm{~d}, J^{4}{ }_{\mathrm{CP}}=2.9\right), 141.95,150.60\left(\mathrm{~d}, J^{2}{ }_{\mathrm{CP}}=7.4\right), 152.96\left(\mathrm{~d}, J^{2}{ }_{\mathrm{CP}}=7.3\right) ; \delta_{\mathrm{P}}(162$ MHz, DMSO-d $\left.d_{6}\right)$ 12.25; ESI-HRMS (m/z) $[\mathrm{M}+\mathrm{H}]^{+}$: calculated for C18H17NO5PS 390.0565; found 390.0563.

\section{Bis(4-sulfamoylphenyl) phenylphosphonate (10).}

Compound 10 was obtained according the general procedure earlier reported using phenylphosphonic dichloride 2 ( $0.5 \mathrm{eq})$, 4-hydroxybenzenesulfonamide $\mathbf{1}$ ( $0.5 \mathrm{~g}, 1.0 \mathrm{eq})$ and trimethylamine (2.2 eq) in dry THF $(10 \mathrm{ml})$. The reaction mixture was concentrated in vacuo and the obtained residue purified by silica gel coloumn chromatography eluting with $10 \% \mathrm{MeOH}$ in DCM to afford the title compound as yellow solid. $38 \%$ yield; m.p. $95-96^{\circ} \mathrm{C}$; silica gel TLC $R_{f} 0.26\left(\mathrm{MeOH} / \mathrm{CH}_{2} \mathrm{Cl}_{2} 10 \% \mathrm{v} / \mathrm{v}\right) ; \delta_{\mathrm{H}}(400$ MHz, DMSO-d 6 ): 7.41 (s, 4H, exchange with $\mathrm{D}_{2} \mathrm{O}, 2$ x $\left.\mathrm{SO}_{2} \mathrm{NH}_{2}\right), 7.47$ (m, 4H, Ar-H), $7.68(\mathrm{~m}, 2 \mathrm{H}$, Ar- $H), 7.80(\mathrm{~m}, 1 \mathrm{H}, \mathrm{Ar}-H), 7.88(\mathrm{~m}, 4 \mathrm{H}, \mathrm{Ar}-H), 8.03(\mathrm{~m}, 2 \mathrm{H}, \mathrm{Ar}-H) ; \delta_{\mathrm{C}}\left(100 \mathrm{MHz}, \mathrm{DMSO}-d_{6}\right): 121.79$ $\left(\mathrm{d}, J^{3}{ }_{\mathrm{CP}}=4.5\right), 125.86\left(\mathrm{~d}, J^{1}{ }_{\mathrm{CP}}=190.10\right), 128.93,130.21\left(\mathrm{~d}, J^{2}{ }_{\mathrm{CP}}=15.9\right), 133.06\left(\mathrm{~d}, J^{3}{ }_{\mathrm{CP}}=11.0\right)$, $135.15,142.14,152.76\left(\mathrm{~d}, J^{2}{ }_{\mathrm{CP}}=6.9\right) ; \delta_{\mathrm{P}}\left(162 \mathrm{MHz}, \mathrm{DMSO}-d_{6}\right) 12.49 ;$ ESI-HRMS $(\mathrm{m} / \mathrm{z})[\mathrm{M}+\mathrm{H}]^{+}$: calculated for C18H18N2O7PS2 469.0293; found 469.0296.

\section{S-Ethyl O-(4-sulfamoylphenyl) phenylphosphonothioate (11).}

Compound 11 was obtained according the general procedure earlier reported using mercaptoethanol (2.0 eq), phenylphosphonic dichloride 2 (1.2 eq), 4-hydroxybenzenesulfonamide $\mathbf{1}$ ( $0.3 \mathrm{~g}, 1.0 \mathrm{eq})$ and trimethylamine $(2.2 \mathrm{eq})$ in dry THF $(10 \mathrm{ml})$. The reaction mixture was concentrated in vacuo and the obtained residue purified by silica gel coloumn chromatography eluting with $4 \% \mathrm{MeOH}$ in DCM to 
afford the title compound as white solid. $36 \%$ yield; m.p. $109-110^{\circ} \mathrm{C}$; silica gel TLC $R_{f} 0.39$ $\left(\mathrm{MeOH} / \mathrm{CH}_{2} \mathrm{Cl}_{2} 10 \% \mathrm{v} / \mathrm{v}\right) ; \delta_{\mathrm{H}}\left(400 \mathrm{MHz}, \mathrm{DMSO}-d_{6}\right): 1.16\left(\mathrm{t}, J=7.4,3 \mathrm{H}, \mathrm{CH}_{2} \mathrm{CH}_{3}\right), 2.83(\mathrm{~m}, 2 \mathrm{H}$, $\left.\mathrm{SCH}_{2}\right), 7.43\left(\mathrm{~s}, 2 \mathrm{H}\right.$, exchange with $\left.\mathrm{D}_{2} \mathrm{O}, \mathrm{SO}_{2} \mathrm{NH}_{2}\right), 7.54(\mathrm{~m}, 2 \mathrm{H}, \mathrm{Ar}-H), 7.68(\mathrm{~m}, 2 \mathrm{H}, \mathrm{Ar}-H), 7.77$ (m, 1H, Ar- $H), 7.91(\mathrm{~m}, 2 \mathrm{H}, \operatorname{Ar}-H), 8.00(\mathrm{~m}, 2 \mathrm{H}, \mathrm{Ar}-H) ; \delta_{\mathrm{C}}\left(100 \mathrm{MHz}, \mathrm{DMSO}-d_{6}\right): 16.93\left(\mathrm{~d}, J^{2}{ }_{\mathrm{CP}}=4.9\right)$, $25.75\left(\mathrm{~d}, J^{3}{ }_{\mathrm{CP}}=3.0\right), 122.25\left(\mathrm{~d}, J^{3}{ }_{\mathrm{CP}}=4.7\right), 128.79,130.6\left(\mathrm{~d}, J^{2}{ }_{\mathrm{CP}}=14.7\right), 131.79\left(\mathrm{~d}, J^{3}{ }_{\mathrm{CP}}=11.5\right)$, $132.33\left(\mathrm{~d}, J^{1}{ }_{\mathrm{CP}}=147.1\right), 134.40\left(\mathrm{~d}, J^{4}{ }_{\mathrm{CP}}=3.3\right), 141.91,153.24\left(\mathrm{~d}, J^{2}{ }_{\mathrm{CP}}=9.1\right) ; \delta_{\mathrm{P}}(162 \mathrm{MHz}, \mathrm{DMSO}-$ $\left.d_{6}\right)$ 43.52; ESI-HRMS (m/z) $[\mathrm{M}+\mathrm{H}]^{+}$: calculated for C14H15NO4PS2 356.0180; found 356.0176.

\section{S-Dodecyl O-(4-sulfamoylphenyl) phenylphosphonothioate (12).}

Compound 12 was obtained according the general procedure earlier reported using 1-dodecanethiol (2.0 eq), phenylphosphonic dichloride $\mathbf{2}$ (1.2 eq), 4-hydroxybenzenesulfonamide $\mathbf{1}$ (0.3 g, $1.0 \mathrm{eq})$ and trimethylamine $(2.2 \mathrm{eq})$ in dry THF $(10 \mathrm{ml})$. The reaction mixture was concentrated in vacuo and the obtained residue purified by silica gel coloumn chromatography eluting with $4 \% \mathrm{MeOH}$ in DCM to afford the title compound as white waxy solid. $29 \%$ yield; m.p. $62-63^{\circ} \mathrm{C}$; silica gel TLC $R_{f} 0.45$ $\left(\mathrm{MeOH} / \mathrm{CH}_{2} \mathrm{Cl}_{2} 10 \% \mathrm{v} / \mathrm{v}\right) ; 0.89\left(\mathrm{t}, J=7.0,3 \mathrm{H}, \mathrm{CH}_{2} \mathrm{CH}_{3}\right), 1.21\left(\mathrm{~m}, 18 \mathrm{H}, 9 \times \mathrm{CH}_{2}\right), 1.46\left(\mathrm{~m}, 2 \mathrm{H}, \mathrm{CH}_{2}\right)$, $2.81\left(\mathrm{~m}, 2 \mathrm{H}, \mathrm{CH}_{2}\right), 7.42\left(\mathrm{~s}, 2 \mathrm{H}\right.$, exchange with $\left.\mathrm{D}_{2} \mathrm{O}, \mathrm{SO}_{2} \mathrm{NH}_{2}\right), 7.53(\mathrm{~m}, 2 \mathrm{H}, \mathrm{Ar}-H), 7.67(\mathrm{~m}, 2 \mathrm{H}, \mathrm{Ar}-$ $H), 7.76(\mathrm{~m}, 1 \mathrm{H}, \operatorname{Ar}-H), 7.90(\mathrm{~m}, 2 \mathrm{H}, \mathrm{Ar}-H), 7.99$ (m, 2H, Ar- $H)$; $\delta_{\mathrm{C}}\left(100 \mathrm{MHz}, \mathrm{DMSO}-d_{6}\right):$ 14.84, $22.98,28.45,29.08,29.57,29.61,29.75,29.85,29.86,30.76\left(\mathrm{~d}, J^{2}{ }_{\mathrm{CP}}=4.5\right), 31.09\left(\mathrm{~d}, J^{3}{ }_{\mathrm{CP}}=2.9\right)$, $32.18,122.19\left(\mathrm{~d}, J^{3}{ }_{\mathrm{CP}}=5.0\right), 128.76,130.0\left(\mathrm{~d}, J^{2}{ }_{\mathrm{CP}}=14.8\right), 131.89\left(\mathrm{~d}, J^{3}{ }_{\mathrm{CP}}=11.2\right), 132.34(\mathrm{~d}, J$ $\left.{ }^{1}{ }_{\mathrm{CP}}=147.1\right), 134.36\left(\mathrm{~d}, J^{4}{ }_{\mathrm{CP}}=3.3\right), 141.96,153.23\left(\mathrm{~d}, J^{2}{ }_{\mathrm{CP}}=9.1\right) ; \delta_{\mathrm{P}}\left(162 \mathrm{MHz}, \mathrm{DMSO}-d_{6}\right) 43.65 ;$ ESI-HRMS (m/z) [M+H] $]^{+}$: calculated for C24H37NO4PS2 498.1901; found 498.1896.

\section{S-Benzyl O-(4-sulfamoylphenyl) phenylphosphonothioate (13).}

Compound 13 was obtained according the general procedure earlier reported using benzylmercaptan (2.0 eq), phenylphosphonic dichloride $\mathbf{2}$ (1.2 eq), 4-hydroxybenzenesulfonamide $\mathbf{1}(0.3 \mathrm{~g}, 1.0 \mathrm{eq})$ and 
trimethylamine $(2.2 \mathrm{eq})$ in dry THF $(10 \mathrm{ml})$. The reaction mixture was concentrated in vacuo and the obtained residue purified by silica gel coloumn chromatography eluting with $4 \% \mathrm{MeOH}$ in DCM to afford the title compound as white solid. $57 \%$ yield; m.p. $201-202^{\circ} \mathrm{C}$; silica gel TLC $R_{f} 0.52$ $\left(\mathrm{MeOH} / \mathrm{CH}_{2} \mathrm{Cl}_{2} 10 \% \mathrm{v} / \mathrm{v}\right) ; \delta_{\mathrm{H}}\left(400 \mathrm{MHz}, \mathrm{DMSO}-d_{6}\right): 4.10\left(\mathrm{~m}, 2 \mathrm{H}, \mathrm{SCH} H_{2}\right), 7.19(\mathrm{~m}, 2 \mathrm{H}, \mathrm{Ar}-H), 7.26$ (m, 3H, Ar-H), $7.43\left(\mathrm{~s}, 2 \mathrm{H}\right.$, exchange with $\left.\mathrm{D}_{2} \mathrm{O}, \mathrm{SO}_{2} \mathrm{NH}_{2}\right), 7.50(\mathrm{~m}, 2 \mathrm{H}, \mathrm{Ar}-H), 7.65(\mathrm{~m}, 2 \mathrm{H}, \mathrm{Ar}-H)$, $7.75(\mathrm{~m}, 1 \mathrm{H}, \mathrm{Ar}-H), 7.89(\mathrm{~m}, 2 \mathrm{H}, \mathrm{Ar}-H), 7.97$ (m, 2H, Ar- $H) ; \delta_{\mathrm{C}}\left(100 \mathrm{MHz}, \mathrm{DMSO}-d_{6}\right): 34.83(\mathrm{~d}, J$ $\left.{ }^{2}{ }_{\mathrm{CP}}=2.9\right), 122.5\left(\mathrm{~d}, J^{3}{ }_{\mathrm{CP}}=5.0\right), 128.40,128.74,129.41,129.64,129.99\left(\mathrm{~d}, J^{2}{ }_{\mathrm{CP}}=14.8\right), 131.89(\mathrm{~d}$, $\left.J^{3}{ }_{\mathrm{CP}}=11.3\right), 132.04\left(\mathrm{~d}, J^{1}{ }_{\mathrm{CP}}=148.5\right), 134.39\left(\mathrm{~d}, J^{4}{ }_{\mathrm{CP}}=3.1\right), 137.65\left(\mathrm{~d}, J^{3}{ }_{\mathrm{CP}}=5.0\right), 141.96,153.23$ $\left(\mathrm{d}, J_{\mathrm{CP}}=9.1\right) ; \delta_{\mathrm{P}}\left(162 \mathrm{MHz}, \mathrm{DMSO}-d_{6}\right)$ 42.64; ESI-HRMS $(\mathrm{m} / \mathrm{z})[\mathrm{M}+\mathrm{H}]^{+}:$calculated for C19H19NO4PS2 420.0493; found 420.0487.

\section{S-Phenyl O-(4-sulfamoylphenyl) phenylphosphonothioate (14).}

Compound 14 was obtained according the general procedure earlier reported using thiophenol (2.0 eq), phenylphosphonic dichloride 2 (1.2 eq), 4-hydroxybenzenesulfonamide 1 (0.3 g, $1.0 \mathrm{eq})$ and trimethylamine $(2.2 \mathrm{eq})$ in dry THF $(10 \mathrm{ml})$. The reaction mixture was concentrated in vacuo and the obtained residue purified by silica gel coloumn chromatography eluting with $4 \% \mathrm{MeOH}$ in $\mathrm{DCM}$ to afford the title compound as white solid. $47 \%$ yield; m.p. $117-118^{\circ} \mathrm{C}$; silica gel TLC $R_{f} 0.40$ $\left(\mathrm{MeOH} / \mathrm{CH}_{2} \mathrm{Cl}_{2} 10 \% \mathrm{v} / \mathrm{v}\right) ; \delta_{\mathrm{H}}\left(400 \mathrm{MHz}, \mathrm{DMSO}-d_{6}\right): 7.33(\mathrm{~m}, 4 \mathrm{H}, \mathrm{Ar}-H), 7.44(\mathrm{~m}, 1 \mathrm{H}, \mathrm{Ar}-H), 7.45$ (s, 2H, exchange with $\mathrm{D}_{2} \mathrm{O}, \mathrm{SO}_{2} \mathrm{NH}_{2}$, overlap with signal at 7.44), $7.53(\mathrm{~m}, 2 \mathrm{H}, \mathrm{Ar}-\mathrm{H}), 7.59(\mathrm{~m}, 2 \mathrm{H}$, Ar- $H), 7.72(\mathrm{~m}, 1 \mathrm{H}, \mathrm{Ar}-H), 7.81(\mathrm{~m}, 2 \mathrm{H}, \mathrm{Ar}-H), 7.92(\mathrm{~m}, 2 \mathrm{H}, \mathrm{Ar}-H) ; \delta_{\mathrm{C}}\left(100 \mathrm{MHz}, \mathrm{DMSO}-d_{6}\right): 121.99$ $\left(\mathrm{d}, J^{3}{ }_{\mathrm{CP}}=5.1\right), 125.50\left(\mathrm{~d}, J^{3}{ }_{\mathrm{CP}}=5.3\right), 128.88,129.82\left(\mathrm{~d}, J^{2}{ }_{\mathrm{CP}}=14.9\right), 130.51,130.61,130.71(\mathrm{~d}, J$ $\left.{ }_{\mathrm{CP}}^{1}=147.8\right), 132.27\left(\mathrm{~d}, J^{3}{ }_{\mathrm{CP}}=11.1\right), 134.59\left(\mathrm{~d}, J^{4}{ }_{\mathrm{CP}}=3.3\right), 136.13\left(\mathrm{~d}, J^{2}{ }_{\mathrm{CP}}=4.4\right), 142.03,153.25$ $\left(\mathrm{d}, J_{\mathrm{CP}}=9.5\right) ; \delta_{\mathrm{P}}\left(162 \mathrm{MHz}, \mathrm{DMSO}-d_{6}\right)$ 39.97; ESI-HRMS $(\mathrm{m} / \mathrm{z})[\mathrm{M}+\mathrm{H}]^{+}:$calculated for C18H17NO4PS2 406.0336; found 406.0329.

\section{4-Sulfamoylphenyl P-phenylphosphonamidate (15).}


Compound 15 was obtained according the general procedure earlier reported using $\mathrm{NH}_{3(\mathrm{aq})}(5.0 \mathrm{eq})$, phenylphosphonic dichloride 2 (1.2 eq), 4-hydroxybenzenesulfonamide 1 (0.3 g, 1.0 eq) and trimethylamine $(2.2 \mathrm{eq})$ in dry THF $(10 \mathrm{ml})$. The formed precipitate was filtered-off, washed with water and recrystallized from EtOH to afford the title compound as white solid. 51\% yield; m.p. 227$228^{\circ} \mathrm{C}$; silica gel TLC $R_{f} 0.21\left(\mathrm{MeOH} / \mathrm{CH}_{2} \mathrm{Cl}_{2} 10 \% \mathrm{v} / \mathrm{v}\right) ; \delta_{\mathrm{H}}\left(400 \mathrm{MHz}, \mathrm{DMSO}-d_{6}\right): 5.36(\mathrm{~d}, J=5.6$, $2 \mathrm{H}$, exchange with $\left.\mathrm{D}_{2} \mathrm{O}, \mathrm{PON} H_{2}\right), 7.31\left(\mathrm{~s}, 2 \mathrm{H}\right.$, exchange with $\left.\mathrm{D}_{2} \mathrm{O}, \mathrm{SO}_{2} \mathrm{NH}_{2}\right), 7.35(\mathrm{~d}, J=8.4,2 \mathrm{H}$, $\operatorname{Ar}-H), 7.53(\mathrm{~m}, 2 \mathrm{H}, \operatorname{Ar}-H), 7.56(\mathrm{~m}, 1 \mathrm{H}, \operatorname{Ar}-H), 7.78(\mathrm{~d}, J=8.4,2 \mathrm{H}, \operatorname{Ar}-H), 7.84(\mathrm{~m}, 2 \mathrm{H}, \operatorname{Ar}-H) ; \delta_{\mathrm{C}}$ $\left(100 \mathrm{MHz}, \mathrm{DMSO}-d_{6}\right): 121.9\left(\mathrm{~d}, J^{3}{ }_{\mathrm{CP}}=4.7\right), 128.36,129.26\left(\mathrm{~d}, J^{2}{ }_{\mathrm{CP}}=14.3\right), 131.73\left(\mathrm{~d}, J^{3}{ }_{\mathrm{CP}}=10.3\right)$, $132.73\left(\mathrm{~d}, J^{4}{ }_{\mathrm{CP}}=3.0\right), 133.37\left(\mathrm{~d}, J^{1}{ }_{\mathrm{CP}}=171.3\right), 140.65,154.31\left(\mathrm{~d}, J^{2}{ }_{\mathrm{CP}}=7.5\right) ; \delta_{\mathrm{P}}(162 \mathrm{MHz}, \mathrm{DMSO}-$ $\left.d_{6}\right)$ 22.23; ESI-HRMS (m/z) [M+H] $]^{+}$: calculated for C12H13N2O4PS 312.0333; found 312.0328.

\section{4-Sulfamoylphenyl P-phenyl-N-propylphosphonamidate (16).}

Compound 16 was obtained according the general procedure earlier reported using propylamine (3.0 eq), phenylphosphonic dichloride 2 (1.2 eq), 4-hydroxybenzenesulfonamide 1 (0.3 g, 1.0 eq) and trimethylamine $(2.2 \mathrm{eq})$ in dry THF $(10 \mathrm{ml})$. The reaction mixture was concentrated in vacuo and the obtained residue purified by silica gel coloumn chromatography eluting with $4 \% \mathrm{MeOH}$ in $\mathrm{DCM}$ to afford the title compound as white solid. $46 \%$ yield; m.p. $137-138^{\circ} \mathrm{C}$; silica gel TLC $R_{f} 0.15$ $\left(\mathrm{MeOH} / \mathrm{CH}_{2} \mathrm{Cl}_{2} 5 \% \mathrm{v} / \mathrm{v}\right) ; \delta_{\mathrm{H}}\left(400 \mathrm{MHz}, \mathrm{DMSO}-d_{6}\right): 0.79\left(\mathrm{t}, J=7.4,3 \mathrm{H}, \mathrm{CH}_{2} \mathrm{CH}_{3}\right), 1.38(\mathrm{~m}, 2 \mathrm{H}$, $\left.\mathrm{CH}_{2} \mathrm{CH}_{3}\right), 2.85\left(\mathrm{~m}, 2 \mathrm{H}, \mathrm{NHCH}_{2}\right), 5.64\left(\mathrm{~m}, 1 \mathrm{H}\right.$, exchange with $\left.\mathrm{D}_{2} \mathrm{O}, \mathrm{PONH}\right), 7.35(\mathrm{~s}, 2 \mathrm{H}$, exchange with $\left.\mathrm{D}_{2} \mathrm{O}, \mathrm{SO}_{2} \mathrm{NH}_{2}\right), 7.43(\mathrm{~m}, 2 \mathrm{H}, \mathrm{Ar}-H), 7.60$ (m, 3H, Ar- $\left.H\right), 7.86$ (m, 4H, Ar- $\left.H\right)$; $\delta_{\mathrm{C}}(100 \mathrm{MHz}$, DMSO- $\left.d_{6}\right): 12.06,25.42\left(\mathrm{~d}, J^{3}{ }_{\mathrm{CP}}=5.5\right), 43.09,121.77\left(\mathrm{~d}, J^{3}{ }_{\mathrm{CP}}=4.9\right), 128.47,129.50\left(\mathrm{~d}, J^{2}{ }_{\mathrm{CP}}=\right.$ $14.5), 131.95\left(\mathrm{~d}, J^{3}{ }_{\mathrm{CP}}=9.8\right), 132.09\left(\mathrm{~d}, J^{1}{ }_{\mathrm{CP}}=173.1\right), 132.98\left(\mathrm{~d}, J^{4}{ }_{\mathrm{CP}}=3.0\right), 140.78,154.27\left(\mathrm{~d}, J^{2}{ }_{\mathrm{CP}}\right.$ $=7.8) ; \delta_{\mathrm{P}}\left(162 \mathrm{MHz}, \mathrm{DMSO}-d_{6}\right) 21.26$; ESI-HRMS $(\mathrm{m} / \mathrm{z})[\mathrm{M}+\mathrm{H}]^{+}$: calculated for $\mathrm{C} 15 \mathrm{H} 20 \mathrm{~N} 2 \mathrm{O} 4 \mathrm{PS}$ 355.0881; found 355.0880 . 


\section{4-Sulfamoylphenyl N,N-diethyl-P-phenylphosphonamidate (17).}

Compound 17 was obtained according the general procedure earlier reported using diethylamine (3.0 eq), phenylphosphonic dichloride 2 (1.2 eq), 4-hydroxybenzenesulfonamide 1 ( $0.3 \mathrm{~g}, 1.0$ eq) and trimethylamine $(2.2 \mathrm{eq})$ in dry THF $(10 \mathrm{ml})$. The reaction mixture was concentrated in vacuo and the obtained residue purified by silica gel coloumn chromatography eluting with $4 \% \mathrm{MeOH}$ in DCM to afford the title compound as white solid. $35 \%$ yield; m.p. $130-131^{\circ} \mathrm{C}$; silica gel TLC $R_{f} 0.40$ $\left(\mathrm{MeOH} / \mathrm{CH}_{2} \mathrm{Cl}_{2} 10 \% \mathrm{v} / \mathrm{v}\right) ; \delta_{\mathrm{H}}\left(400 \mathrm{MHz}, \mathrm{DMSO}-d_{6}\right): 0.92\left(\mathrm{t}, J=7.2,6 \mathrm{H}, 2 \mathrm{x} \mathrm{CH}_{2} \mathrm{CH}_{3}\right), 3.12(\mathrm{~m}, 4 \mathrm{H}$, 2x $\left.\mathrm{CH}_{2} \mathrm{CH}_{3}\right), 7.38$ (s, 2H, exchange with $\left.\mathrm{D}_{2} \mathrm{O}, \mathrm{SO}_{2} \mathrm{NH}_{2}\right), 7.52(\mathrm{~m}, 2 \mathrm{H}, \mathrm{Ar}-H), 7.60(\mathrm{~m}, 2 \mathrm{H}, \mathrm{Ar}-H)$, $7.67(\mathrm{~m}, 1 \mathrm{H}, \mathrm{Ar}-H), 7.88(\mathrm{~m}, 4 \mathrm{H}, \mathrm{Ar}-H) ; \delta_{\mathrm{C}}\left(100 \mathrm{MHz}, \mathrm{DMSO}-d_{6}\right): 14.63\left(\mathrm{~d}, J^{3}{ }_{\mathrm{CP}}=2.0\right), 39.31(\mathrm{~d}, J$ $\left.{ }^{2}{ }_{\mathrm{CP}}=4.6\right), 121.58\left(\mathrm{~d}, J^{3}{ }_{\mathrm{CP}}=5.0\right), 128.57,129.68\left(\mathrm{~d}, J^{2}{ }_{\mathrm{CP}}=14.4\right), 131.4\left(\mathrm{~d}, J^{1}{ }_{\mathrm{CP}}=177.9\right), 131.91(\mathrm{~d}$, $\left.J^{3}{ }_{\mathrm{CP}}=9.9\right), 133.07\left(\mathrm{~d}, J^{4}{ }_{\mathrm{CP}}=2.9\right), 140.96,154.05\left(\mathrm{~d}, J^{2}{ }_{\mathrm{CP}}=8.0\right) ; \delta_{\mathrm{P}}\left(162 \mathrm{MHz}, \mathrm{DMSO}-d_{6}\right) 21.20 ;$ ESI-HRMS (m/z) [M+H] $]^{+}$: calculated for C16H22N2O4PS 369.1038; found 369.1032.

\section{4-Sulfamoylphenyl phenyl(pyrrolidin-1-yl)phosphinate (18).}

Compound 18 was obtained according the general procedure earlier reported using pyrrolidine (3.0 eq), phenylphosphonic dichloride 2 (1.2 eq), 4-hydroxybenzenesulfonamide 1 (0.3 g, 1.0 eq) and trimethylamine $(2.2 \mathrm{eq})$ in dry THF $(10 \mathrm{ml})$. The reaction mixture was concentrated in vacuo and the obtained residue purified by silica gel coloumn chromatography eluting with $4 \% \mathrm{MeOH}$ in DCM to afford the title compound as white solid. $58 \%$ yield; m.p. $118-119^{\circ} \mathrm{C}$; silica gel TLC $R_{f} 0.56$ $\left(\mathrm{MeOH} / \mathrm{CH}_{2} \mathrm{Cl}_{2} 10 \% \mathrm{v} / \mathrm{v}\right) ; \delta_{\mathrm{H}}\left(400 \mathrm{MHz}, \mathrm{DMSO}-d_{6}\right): 1.74(\mathrm{~m}, 4 \mathrm{H}, 2 \mathrm{x} \mathrm{CH}), 3.17\left(\mathrm{~m}, 4 \mathrm{H}, 2 \mathrm{x} \mathrm{CH} \mathrm{CH}_{2}\right)$, 7.39 (s, 2H, exchange with $\left.\mathrm{D}_{2} \mathrm{O}, \mathrm{SO}_{2} \mathrm{NH}_{2}\right), 7.50(\mathrm{~m}, 2 \mathrm{H}, \mathrm{Ar}-H), 7.60(\mathrm{~m}, 2 \mathrm{H}, \mathrm{Ar}-H), 7.67(\mathrm{~m}, 1 \mathrm{H}$, $\operatorname{Ar}-H), 7.87(\mathrm{~m}, 4 \mathrm{H}, \operatorname{Ar}-H) ; \delta_{\mathrm{C}}\left(100 \mathrm{MHz}, \mathrm{DMSO}-d_{6}\right): 26.63\left(\mathrm{~d}, J^{2}{ }_{\mathrm{CP}}=8.1\right), 47.31\left(\mathrm{~d}, J^{3}{ }_{\mathrm{CP}}=4.4\right)$, $121.46\left(\mathrm{~d}, J^{3}{ }_{\mathrm{CP}}=5.1\right), 128.66,129.71\left(\mathrm{~d}, J^{2}{ }_{\mathrm{CP}}=14.1\right), 130.44\left(\mathrm{~d}, J^{1}{ }_{\mathrm{CP}}=173.2\right), 131.90\left(\mathrm{~d}, J^{3}{ }_{\mathrm{CP}}=\right.$ 9.6), $133.19\left(\mathrm{~d}, J^{4}{ }_{\mathrm{CP}}=2.9\right), 140.99,154.06\left(\mathrm{~d}, J^{2}{ }_{\mathrm{CP}}=7.5\right) ; \delta_{\mathrm{P}}\left(162 \mathrm{MHz}, \mathrm{DMSO}-d_{6}\right) 18.85$; ESIHRMS (m/z) [M+H] $]^{+}$: calculated for C16H20N2O4PS 367.0881; found 367.0875. 


\section{4-Sulfamoylphenyl morpholino(phenyl)phosphinate (19).}

Compound 19 was obtained according the general procedure earlier reported using morpholine (3.0 eq), phenylphosphonic dichloride 2 (1.2 eq), 4-hydroxybenzenesulfonamide 1 (0.3 g, 1.0 eq) and trimethylamine $(2.2 \mathrm{eq})$ in dry THF $(10 \mathrm{ml})$. The reaction mixture was concentrated in vacuo and the obtained residue purified by silica gel coloumn chromatography eluting with $4 \% \mathrm{MeOH}$ in DCM to afford the title compound as white solid. $49 \%$ yield; m.p. $125-126^{\circ} \mathrm{C}$; silica gel TLC $R_{f} 0.15$ $\left(\mathrm{MeOH} / \mathrm{CH}_{2} \mathrm{Cl}_{2} 5 \% \mathrm{v} / \mathrm{v}\right) ; \delta_{\mathrm{H}}\left(400 \mathrm{MHz}, \mathrm{DMSO}-d_{6}\right): 3.09\left(\mathrm{~m}, 4 \mathrm{H}, 2 \mathrm{x} \mathrm{CH} \mathrm{CH}_{2}\right), 3.45\left(\mathrm{~m}, 4 \mathrm{H}, 2 \mathrm{x} \mathrm{CH} \mathrm{CH}_{2}\right)$, $7.41\left(\mathrm{~s}, 2 \mathrm{H}\right.$, exchange with $\left.\mathrm{D}_{2} \mathrm{O}, \mathrm{SO}_{2} \mathrm{NH}_{2}\right), 7.54(\mathrm{~m}, 2 \mathrm{H}, \mathrm{Ar}-H), 7.63(\mathrm{~m}, 2 \mathrm{H}, \mathrm{Ar}-H), 7.70(\mathrm{~m}, 1 \mathrm{H}$, Ar- $H), 7.90(\mathrm{~m}, 4 \mathrm{H}, \mathrm{Ar}-H) ; \delta_{\mathrm{C}}\left(100 \mathrm{MHz}, \mathrm{DMSO}-d_{6}\right): 44.58,66.95\left(\mathrm{~d}, J^{2}{ }_{\mathrm{CP}}=5.1\right), 121.75\left(\mathrm{~d}, J^{3}{ }_{\mathrm{CP}}\right.$ $=5.1), 128.73,129.88\left(\mathrm{~d}, J^{2}{ }_{\mathrm{CP}}=14.3\right), 130.00\left(\mathrm{~d}, J^{1}{ }_{\mathrm{CP}}=177.6\right), 132.10\left(\mathrm{~d}, J^{3}{ }_{\mathrm{CP}}=9.7\right), 133.47(\mathrm{~d}, J$ $\left.{ }_{\mathrm{CP}}^{4}=3.0\right), 141.28,153.83\left(\mathrm{~d}, J^{2}{ }_{\mathrm{CP}}=8.0\right) ; \delta_{\mathrm{P}}\left(162 \mathrm{MHz}, \mathrm{DMSO}-d_{6}\right) 19.24 ;$ ESI-HRMS $(\mathrm{m} / \mathrm{z})[\mathrm{M}+\mathrm{H}]^{+}:$ calculated for $\mathrm{C} 16 \mathrm{H} 20 \mathrm{~N} 2 \mathrm{O} 5 \mathrm{PS} 383.0830$; found 383.0824 .

\section{4-Sulfamoylphenyl (4-methylpiperazin-1-yl)(phenyl)phosphinate (20).}

Compound $\mathbf{2 0}$ was obtained according the general procedure earlier reported using Nmethylpiperazine (3.0 eq), phenylphosphonic dichloride 2 (1.2 eq), 4-hydroxybenzenesulfonamide 1 $(0.3 \mathrm{~g}, 1.0 \mathrm{eq})$ and trimethylamine $(2.2 \mathrm{eq})$ in dry THF $(10 \mathrm{ml})$. The reaction mixture was concentrated in vacuo and the obtained residue purified by silica gel coloumn chromatography eluting with $4 \%$ $\mathrm{MeOH}$ in DCM to afford the title compound as white solid. $41 \%$ yield; m.p. $135-136^{\circ} \mathrm{C}$; silica gel TLC $R_{f} 0.09\left(\mathrm{MeOH} / \mathrm{CH}_{2} \mathrm{Cl}_{2} 10 \% \mathrm{v} / \mathrm{v}\right) ; \delta_{\mathrm{H}}\left(400 \mathrm{MHz}, \mathrm{DMSO}-d_{6}\right): 2.11\left(\mathrm{~s}, 3 \mathrm{H}, \mathrm{NCH}_{3}\right), 2.16(\mathrm{~m}, 4 \mathrm{H}$, 2x $\left.\mathrm{CH}_{2}\right), 3.11(\mathrm{~m}, 4 \mathrm{H}, 2 \mathrm{x} \mathrm{CH}), 7.41\left(\mathrm{~s}, 2 \mathrm{H}\right.$, exchange with $\left.\mathrm{D}_{2} \mathrm{O}, \mathrm{SO}_{2} \mathrm{NH}_{2}\right), 7.53(\mathrm{~m}, 2 \mathrm{H}, \mathrm{Ar}-H), 7.62$ $(\mathrm{m}, 2 \mathrm{H}, \operatorname{Ar}-H), 7.69(\mathrm{~m}, 1 \mathrm{H}, \operatorname{Ar}-H), 7.88(\mathrm{~m}, 4 \mathrm{H}, \operatorname{Ar}-H) ; \delta_{\mathrm{C}}\left(100 \mathrm{MHz}, \mathrm{DMSO}-d_{6}\right): 44.33\left(\mathrm{~d}, J^{3}{ }_{\mathrm{CP}}=\right.$ $1.8), 46.80,55.20\left(\mathrm{~d}, J^{3}{ }_{\mathrm{CP}}=5.4\right), 121.67\left(\mathrm{~d}, J^{3}{ }_{\mathrm{CP}}=4.9\right), 128.64,129.76\left(\mathrm{~d}, J^{2}{ }_{\mathrm{CP}}=14.5\right), 130.39(\mathrm{~d}$, $\left.J^{1}{ }_{\mathrm{CP}}=177.7\right), 132.00\left(\mathrm{~d}, J^{3}{ }_{\mathrm{CP}}=9.9\right), 133.30\left(\mathrm{~d}, J^{4}{ }_{\mathrm{CP}}=2.9\right), 141.18,153.89\left(\mathrm{~d}, J^{2}{ }_{\mathrm{CP}}=8.0\right) ; \delta_{\mathrm{P}}(162$ 
MHz, DMSO-d $\left.d_{6}\right)$ 19.65; ESI-HRMS (m/z) $[\mathrm{M}+\mathrm{H}]^{+}$: calculated for C17H23N3O4PS 396.1146; found 396.1145 .

\section{4-Sulfamoylphenyl N-benzyl-P-phenylphosphonamidate (21).}

Compound 21 was obtained according the general procedure earlier reported using benzylamine (3.0 eq), phenylphosphonic dichloride 2 (1.2 eq), 4-hydroxybenzenesulfonamide 1 (0.3 g, 1.0 eq) and trimethylamine $(2.2 \mathrm{eq})$ in dry THF $(10 \mathrm{ml})$. The reaction mixture was concentrated in vacuo and the obtained residue purified by silica gel coloumn chromatography eluting with $4 \% \mathrm{MeOH}$ in DCM to afford the title compound as white solid. $63 \%$ yield; m.p. $185-186^{\circ} \mathrm{C}$; silica gel TLC $R_{f} 0.40$ $\left(\mathrm{MeOH} / \mathrm{CH}_{2} \mathrm{Cl}_{2} 20 \% \mathrm{v} / \mathrm{v}\right) ; \delta_{\mathrm{H}}\left(400 \mathrm{MHz}, \mathrm{DMSO}-d_{6}\right): 4.14(\mathrm{~m}, 2 \mathrm{H}, \mathrm{NHCH}), 6.23(\mathrm{~m}$, exchange with $\left.\mathrm{D}_{2} \mathrm{O}, \mathrm{PON} H\right), 7.26(\mathrm{~m}, 5 \mathrm{H}, \mathrm{Ar}-H), 7.36\left(\mathrm{~s}, 2 \mathrm{H}\right.$, exchange with $\left.\mathrm{D}_{2} \mathrm{O}, \mathrm{SO}_{2} \mathrm{NH}_{2}\right), 7.40(\mathrm{~m}, 2 \mathrm{H}, \mathrm{Ar}-H)$, $7.57(\mathrm{~m}, 2 \mathrm{H}, \operatorname{Ar}-H), 7.645(\mathrm{~m}, 1 \mathrm{H}, \operatorname{Ar}-H), 7.81(\mathrm{~m}, 2 \mathrm{H}, \operatorname{Ar}-H), 7.88(\mathrm{~m}, 2 \mathrm{H}, \operatorname{Ar}-H) ; \delta_{\mathrm{C}}(100 \mathrm{MHz}$, DMSO- $\left.d_{6}\right): 44.66,121.90\left(\mathrm{~d}, J^{3}{ }_{\mathrm{CP}}=4.5\right), 127.69,128.09,128.47,129.05,129.51\left(\mathrm{~d}, J^{2}{ }_{\mathrm{CP}}=14.5\right)$, $131.85\left(\mathrm{~d}, J^{1}{ }_{\mathrm{CP}}=173.5\right), 132.01\left(\mathrm{~d}, J^{3}{ }_{\mathrm{CP}}=10.2\right), 133.01\left(\mathrm{~d}, J^{4}{ }_{\mathrm{CP}}=2.9\right), 140.91,141.20\left(\mathrm{~d}, J^{3}{ }_{\mathrm{CP}}=\right.$ 5.2), $154.15\left(\mathrm{~d}, J^{2}{ }_{\mathrm{CP}}=7.5\right) ; \delta_{\mathrm{P}}\left(162 \mathrm{MHz}, \mathrm{DMSO}-d_{6}\right)$ 21.26; ESI-HRMS (m/z) $[\mathrm{M}+\mathrm{H}]^{+}$: calculated for C19H20N2O4PS 403.0881; found 403.0875.

\section{4-Sulfamoylphenyl N,P-diphenylphosphonamidate (22).}

Compound 22 was obtained according the general procedure earlier reported using aniline (3.0 eq), phenylphosphonic dichloride 2 (1.2 eq), 4-hydroxybenzenesulfonamide $\mathbf{1}(0.3 \mathrm{~g}, 1.0 \mathrm{eq})$ and trimethylamine $(2.2 \mathrm{eq})$ in dry THF $(10 \mathrm{ml})$. The reaction mixture was concentrated in vacuo and the obtained residue purified by silica gel coloumn chromatography eluting with $4 \% \mathrm{MeOH}$ in DCM to afford the title compound as white solid. $32 \%$ yield; m.p. $187-188^{\circ} \mathrm{C}$; silica gel TLC $R_{f} 0.38$ $\left(\mathrm{MeOH} / \mathrm{CH}_{2} \mathrm{Cl}_{2} 10 \% \mathrm{v} / \mathrm{v}\right) ; \delta_{\mathrm{H}}\left(400 \mathrm{MHz}, \mathrm{DMSO}-d_{6}\right): 6.91(\mathrm{~m}, 1 \mathrm{H}, \mathrm{Ar}-H), 7.13(\mathrm{~m}, 2 \mathrm{H}, \mathrm{Ar}-H), 7.21$ (m, 2H, Ar- $H), 7.36\left(\mathrm{~s}, 2 \mathrm{H}\right.$, exchange with $\left.\mathrm{D}_{2} \mathrm{O}, \mathrm{SO}_{2} \mathrm{NH}_{2}\right), 7.46(\mathrm{~m}, 2 \mathrm{H}, \mathrm{Ar}-H), 7.60(\mathrm{~m}, 2 \mathrm{H}, \mathrm{Ar}-H)$, 
$7.67(\mathrm{~m}, 1 \mathrm{H}, \mathrm{Ar}-H), 7.85(\mathrm{~m}, 2 \mathrm{H}, \mathrm{Ar}-H), 7.93$ (m, 2H, Ar- $H) ; \delta_{\mathrm{C}}\left(100 \mathrm{MHz}, \mathrm{DMSO}-d_{6}\right): 118.86(\mathrm{~d}, J$ $\left.{ }^{3}{ }_{\mathrm{CP}}=6.9\right), 121.75\left(\mathrm{~d}, J^{3} \mathrm{CP}=4.5\right), 122.21,128.61,129.73\left(\mathrm{~d}, J^{2}{ }_{\mathrm{CP}}=14.5\right), 129.96,130.62\left(\mathrm{~d}, J^{1}{ }_{\mathrm{CP}}=\right.$ $172.9), 132.32\left(\mathrm{~d}, J^{2}{ }_{\mathrm{CP}}=10.4\right), 133.64\left(\mathrm{~d}, J^{4}{ }_{\mathrm{CP}}=2.5\right), 141.29,141.39\left(\mathrm{~d}, J^{4}{ }_{\mathrm{CP}}=1.2\right), 153.61\left(\mathrm{~d}, J^{2}{ }_{\mathrm{CP}}\right.$ $=7.6) ; \delta_{\mathrm{P}}\left(162 \mathrm{MHz}, \mathrm{DMSO}-d_{6}\right)$ 15.37; ESI-HRMS $(\mathrm{m} / \mathrm{z})[\mathrm{M}+\mathrm{H}]^{+}$: calculated for $\mathrm{C} 18 \mathrm{H} 18 \mathrm{~N} 2 \mathrm{O} 4 \mathrm{PS}$ 389.0724; found 389.0716 .

\section{Carbonic anhydrase inhibition}

An Applied Photophysics stopped-flow instrument has been used for assaying the $\mathrm{CA}$ catalysed $\mathrm{CO}_{2}$ hydration activity. ${ }^{32}$ Phenol red (at a concentration of $0.2 \mathrm{mM}$ ) has been used as indicator, working at the absorbance maximum of $557 \mathrm{~nm}$, with $20 \mathrm{mM}$ Hepes (pH 7.5) as buffer, and $20 \mathrm{mM} \mathrm{Na}_{2} \mathrm{SO}_{4}$ (for maintaining constant the ionic strength), following the initial rates of the $\mathrm{CA}$-catalysed $\mathrm{CO}_{2}$ hydration reaction for a period of $10-100 \mathrm{~s}$. The $\mathrm{CO}_{2}$ concentrations ranged from 1.7 to $17 \mathrm{mM}$ for the determination of the kinetic parameters and inhibition constants. For each inhibitor at least six traces of the initial $5-10 \%$ of the reaction have been used for determining the initial velocity. The uncatalyzed rates were determined in the same manner and subtracted from the total observed rates. Stock solutions of inhibitor $(0.1 \mathrm{mM})$ were prepared in distilled-deionized water and dilutions up to $0.01 \mathrm{nM}$ were done thereafter with the assay buffer. Inhibitor and enzyme solutions were preincubated together for $1 \mathrm{~h}$ at room temperature prior to assay, in order to allow for the formation of the E-I complex. The inhibition constants were obtained by non-linear least-squares methods using PRISM 3 and the Cheng-Prusoff equation, as reported earlier, ${ }^{43,44}$ and represent the mean from at least three different determinations. All CA isoforms were recombinant ones obtained in-house as reported earlier. ${ }^{30}$

\section{Drug Stability Study}

\section{Chemicals}


Acetonitrile (Chromasolv), methanol (Chromasolv), formic acid (MS grade), ammonium formate, $\mathrm{HCl}, \mathrm{NaCl}, \mathrm{KCl}, \mathrm{Na}_{2} \mathrm{HPO}_{4} 2 \mathrm{H}_{2} \mathrm{O}, \mathrm{KH}_{2} \mathrm{PO}_{4}$ (Reagent grade) and verapamil hydrochloride (analytical standard, used as internal standard) were purchased by Sigma-Aldrich (Milan, Italy). MilliQ water $18 \mathrm{M} \Omega$ was obtained from Millipore's Simplicity system (Milan - Italy). Phosphate buffer solution (PBS) was prepared by adding $8.01 \mathrm{~g} \mathrm{~L}^{-1}$ of $\mathrm{NaCl}, 0.2 \mathrm{~g} \mathrm{~L}^{-1}$ of $\mathrm{KCl}, 1.78 \mathrm{~g} \mathrm{~L}^{-1}$ of $\mathrm{Na}_{2} \mathrm{HPO}_{4} 2 \mathrm{H}_{2} \mathrm{O}$ and $0.27 \mathrm{~g} \mathrm{~L}^{-1}$ of $\mathrm{KH}_{2} \mathrm{PO}_{4}$. Human plasma was collected from healthy male volunteer; each plasma batch was kept at $-80{ }^{\circ} \mathrm{C}$ until use.

\section{Instrumental}

The LC-MS/MS analysis was carried out using a Varian 1200L triple quadrupole system (Palo Alto, CA, USA) equipped by two Prostar 210 pumps, a Prostar 410 autosampler and an Electrospray Source (ESI) operating in positive ions. Raw-data were collected and processed by Varian Workstation vers. 6.8 software. G-Therm 015 thermostatic oven was used to maintain the samples at $37{ }^{\circ} \mathrm{C}$ during the test of degradation. ALC micro centrifugette 4214 was employed to centrifuge the samples.

\section{LC-MS/MS methods}

The chromatographic parameters employed to analyse the samples were tuned to minimize the run time. The column used was a PFP $30 \mathrm{~mm}$ length, $2 \mathrm{~mm}$ internal diameter and $3 \mu \mathrm{m}$ particle size, at constant flow of $0.25 \mathrm{~mL} \mathrm{~min}^{-1}$, employing a binary mobile phases elution gradient. The eluents used were $10 \mathrm{mM}$ formic acid and $5 \mathrm{mM}$ ammonium formate in water solution (solvent $\mathrm{A}$ ) and $10 \mathrm{mM}$ ammonium formate and $5 \mathrm{mM}$ formic acid in methanol (solvent $\mathrm{B}$ ) according to the elution gradient as follows: initial at $90 \%$ solvent $\mathrm{A}$, which was then decreased to $10 \%$ in $4.0 \mathrm{~min}$, kept for $3.0 \mathrm{~min}$, returned to initial conditions in $0.1 \mathrm{~min}$ and maintained for $3.0 \mathrm{~min}$ for reconditioning, to a total run time of $10.0 \mathrm{~min}$.

The column temperature was maintained at $30^{\circ} \mathrm{C}$ and the injection volume was $5 \mu \mathrm{L}$. The ESI source was operated in positive ion mode, using the following setting: $5 \mathrm{kV}$ needle, 42 psi nebulizing gas, $600 \mathrm{~V}$ shield and $20 \mathrm{psi}$ drying gas at $280^{\circ} \mathrm{C}$. The analyses were acquired in Multiple Reaction Monitoring (MRM) and the ion transitions were reported in Table 3. 
Table 3: MRM parameters

\begin{tabular}{|c|c|c|c|}
\hline Compound & $\begin{array}{c}\text { Precursor Ion } \\
(\mathbf{m} / \mathbf{z})\end{array}$ & $\begin{array}{c}\text { Quantifier Ion } \\
\mathbf{( m / \mathbf { z } )} \\
{[\mathbf{C E}(\mathbf{V})]}\end{array}$ & $\begin{array}{c}\text { Qualifier Ion } \\
\mathbf{( m / \mathbf { m } )} \\
{[\mathbf{C E}(\mathbf{V})]}\end{array}$ \\
\hline $\mathbf{6}$ & 356 & $297[20]$ & $314[10]$ \\
\hline $\mathbf{7}$ & 352 & $335[15]$ & $131[25]$ \\
\hline $\mathbf{1 0}$ & 469 & $452[15]$ & $280[35]$ \\
\hline $\mathbf{1 8}$ & 367 & $194[30]$ & $350[20]$ \\
\hline $\mathbf{2 0}$ & 396 & $223[25]$ & $296[40]$ \\
\hline $\mathbf{2 2}$ & 389 & $308[20]$ & $296[30]$ \\
\hline ISTD & 455 & $165[25]$ & $303[25]$ \\
\hline
\end{tabular}

\section{Standard solutions}

Stock solutions of analytes and verapamil hydrochloride (internal standard or ISTD) were prepared in acetonitrile at $1.0 \mathrm{mg} \mathrm{mL}^{-1}$ and stored at $4{ }^{\circ} \mathrm{C}$. The ISTD working solution was prepared in acetonitrile at $15 \mu \mathrm{g} \mathrm{mL}-1$ (ISTD solution). The spiked solutions of each analyte were prepared separately, by diluting the respective stock solutions in mQ water:acetonitrile 80:20 (v/v) solution, to obtain a final concentration of $10 \mu \mathrm{M}$.

\section{Sample preparation}

The sample was prepared adding $10 \mu \mathrm{L}$ of spiked solution to $100 \mu \mathrm{L}$ of tested matrix (PBS or human plasma or $10 \mathrm{mM} \mathrm{HCl}$ ) in microcentrifuge tubes. The obtained solutions correspond to $1 \mu \mathrm{M}$ of analyte. Each set of samples was incubated in triplicate at four different times, 0, 30, 60 and 120 min at $37{ }^{\circ} \mathrm{C}$. Therefore, the matrix stability profile of each analyte was represented by a batch of 12 samples (4 incubation times $\mathrm{x} 3$ replicates). After the incubation, the samples were added with 300 $\mu \mathrm{L}$ of ISTD solution and centrifuged (room temperature for $5 \mathrm{~min}$ at $800 \mathrm{~g}$ ). The supernatants were transferred in autosampler vials and added with $0.6 \mathrm{~mL}$ of $\mathrm{mQ}$ water. The finals solutions were analysed by the LC-MS/MS methods described above.

\section{X-ray Crystallography.}


Native hCA II was produced and purified as previously described. ${ }^{45}$ For hCA VII, a mutated form where the cysteine residues in position 183 and 217 were mutated to serines, was used for crystallographic studies, since we previously reported that this mutant was more suitable for crystallization experiments. ${ }^{46}$ For both enzymes, crystals were obtained by the hanging drop vapor diffusion technique, using as a precipitant solution containing 1.3 M sodium citrate, $60 \mathrm{mM}$ Tris- $\mathrm{HCl}$, pH 8.0 for CA II, and 25\% (w/v) polyethylene glycol 3350, 0.2 M ammonium acetate, $0.1 \mathrm{M}$ Tris$\mathrm{HCl}, \mathrm{pH} 8.5$ for CA VII. Crystals of enzyme-inhibitor complexes were prepared by soaking enzyme crystals in precipitant solutions containing $10 \mathrm{mM}$ inhibitor and using 1/18 hours as soaking time for CA II/VII crystals, respectively.

X-ray diffraction data for both CA II/3 and CA VII/3 adducts were collected at $100 \mathrm{~K}$, using a Rigaku MicroMax-007 HF generator producing $\mathrm{Cu} \mathrm{K \alpha}$ radiation and equipped with a Saturn $944 \mathrm{CCD}$ detector. Prior to cryogenic freezing, crystals were transferred to the respective precipitant solution with the addition of 10/25\% (v/v) glycerol for hCA II/VII, respectively. Data were integrated, merged and scaled using HKL2000. ${ }^{47}$ Crystal parameters and data collection statistics for both adducts are reported in Table $\mathrm{S} 1$.

Phasing and refinement of the complexes were carried out with REFMAC5 ${ }^{48}$ using as starting models the previously solved hCA II (PDB ID: 6H29) ${ }^{33}$ and hCA VII (PDB ID: 6G4T) ${ }^{46}$ structures with water molecules and ligands removed. In both structures, the inhibitor molecule was clearly visible in the difference Fo-Fc map from the early stages of refinement. Restraints on inhibitor bond angles and distances were taken from the Cambridge Structural Database ${ }^{49}$ and topology file was generated using the PRODRG2 server. ${ }^{50}$ Standard restraints were used on protein bond angles and distances throughout refinement. Several rounds of manual rebuilding were performed using the program $\mathrm{O}^{51}$ with careful inspection of the 2Fo-Fc and Fo-Fc electron density maps. The geometric restraints of the final models were analyzed using the programs PROCHECK ${ }^{52}$ and WHATCHECK. ${ }^{53}$ The 
refinement statistics of the final models are summarized in Table S1. The atomic coordinates of the complexes have been deposited in the Protein Data Bank with accession codes 6SDS and 6SDT.

\begin{abstract}
Animals
Male CD-1 albino mice (Envigo, Varese, Italy) weighing approximately 22-25 $\mathrm{g}$ at the beginning of the experimental procedure, were used. Animals were housed in Ce.S.A.L (Centro Stabulazione Animali da Laboratorio, University of Florence) and used at least 1 week after their arrival. Ten mice were housed per cage (size $26 \times 41 \mathrm{~cm}$ ); animals were fed a standard laboratory diet and tap water $\mathrm{ad}$ libitum, and kept at $23 \pm 1{ }^{\circ} \mathrm{C}$ with a $12 \mathrm{~h} \mathrm{light/dark} \mathrm{cycle,} \mathrm{light} \mathrm{at} 7$ a.m. All animal manipulations were carried out according to the Directive 2010/63/EU of the European parliament and of the European Union council (22 September 2010) on the protection of animals used for scientific purposes. The ethical policy of the University of Florence complies with the Guide for the Care and Use of Laboratory Animals of the US National Institutes of Health (NIH Publication No. 85-23, revised 1996; University of Florence assurance number: A5278-01). Formal approval to conduct the experiments described was obtained from the Animal Subjects Review Board of the University of Florence. Experiments involving animals have been reported according to ARRIVE guidelines. ${ }^{54}$ All efforts were made to minimize animal suffering and to reduce the number of animals used.
\end{abstract}

\title{
Oxaliplatin-induced neuropathic pain model and pharmacological treatments
}

Mice treated with oxaliplatin $\left(2.4 \mathrm{mg} \mathrm{kg}^{-1}\right)$ were administered intraperitoneally (i.p.) on days 1-2, 5 9, 12-14 (10 i.p. injections). ${ }^{55}$ Oxaliplatin was dissolved in 5\% glucose solution. Control animals received an equivalent volume of vehicle. Behavioural tests were performed starting from day 15 . Acetazolamide (AAZ; $\left.100 \mathrm{mg} \mathrm{kg}^{-1}\right)$, duloxetine $\left(15 \mathrm{mg} \mathrm{kg}^{-1}\right)$ and compounds 6, 7, 10, 20 and 22 (10 - $100 \mathrm{mg} \mathrm{kg}^{-1}$ ) and enantiomers $(R)-7$ and $(S)-7$, both $50 \mathrm{mg} \mathrm{kg}^{-1}$, were suspended in $1 \%$ carboxymethylcellulose sodium salt (CMC, Sigma-Aldrich, Milan, Italy) and per os (p.o.) acutely 
administered. Behavioural tests were carried out before and after (15, 30, 45 and $60 \mathrm{~min})$ compound's injection.

\title{
Cold plate
}

Thermal allodynia was assessed using the Cold-plate test. With minimal animal-handler interaction, mice were taken from home-cages, and placed onto the surface of the cold-plate (Ugo Basile, Varese, Italy) maintained at a constant temperature of $4^{\circ} \mathrm{C} \pm 1^{\circ} \mathrm{C}$. Ambulation was restricted by a cylindrical Plexiglas chamber (diameter: $10 \mathrm{~cm}$, height: $15 \mathrm{~cm}$ ), with open top. A timer controlled by foot peddle began timing response latency from the moment the mouse was placed onto the cold-plate. Pain-related behaviour (licking of the hind paw) was observed, and the time (seconds) of the first sign was recorded. The cut-off time of the latency of paw lifting or licking was set at 30 s. ${ }^{56}$

\begin{abstract}
Statistical analysis
Behavioural measurements were performed on 12 mice for each treatment carried out in 2 different experimental sets. Results were expressed as mean \pm S.E.M. The analysis of variance of behavioural data was performed by one-way ANOVA, a Bonferroni's significant difference procedure was used as post-hoc comparison. $P$ values of less than 0.05 or 0.01 were considered significant. Investigators were blind to all experimental procedures. Data were analysed using the "Origin 9" software (OriginLab, Northampton, USA).
\end{abstract}




\section{Enantioseparation and assignment of absolute configuration}

Semipreparative HPLC separations of the enantiomers of 7 was carried out on the commercially available $250 \mathrm{~mm} \times 10 \mathrm{~mm}$ I.D. Chiralpak IA (Chiral Technologies Europe, Illkirch, France) column using the mixture n-hexane-EtOH-MeOH-TFA 60:35:5:0.1 (v/v/v/v) as a mobile phase. The temperature was set at $15^{\circ} \mathrm{C}$. The flow-rate was $4.5 \mathrm{~mL} \mathrm{~min}^{-1}$. HPLC apparatus consisted of a Perkin-Elmer (Norwalk, CT, USA) 200 LC pump equipped with a Rheodyne (Cotati, CA, USA) injector, a $5 \mathrm{~mL}$ sample loop, an HPLC Perkin-Elmer oven and a Perkin-Elmer detector. The signal was acquired and processed by Clarity software (DataApex, Prague, Czech Republic). The amount of racemic samples resolved for single chromatographic run was $1 \mathrm{mg}$.

The CD spectra of enantiomers of 7 , dissolved in ethanol (concentration about $0.40 \mathrm{mg} \mathrm{mL}$ ${ }^{-1}$ ) in $0.1 \mathrm{~cm}$ path-length quartz cell at $25^{\circ} \mathrm{C}$, were measured by using a Jasco Model J-700 spectropolarimeter. The spectra are average computed over three instrumental scans and the intensities are presented in terms of ellipticity values (mdeg).

Specific rotations were measured at $589,578,546,436,365$ and $302 \mathrm{~nm}$ by a PerkinElmer polarimeter model 241 equipped with $\mathrm{Na} / \mathrm{Hg}$ lamps. The volume of the cell was $1 \mathrm{~mL}$ and the optical path was $10 \mathrm{~cm}$. The system was set at a temperature of $20^{\circ} \mathrm{C}$. 
The in silico procedure adopted to achieve the assignment of absolute configuration can be summarized in the following five steps: (i) conduction of a conformational search based on molecular mechanic calculations (MM) performed on the structure of 7 characterized by $(\boldsymbol{R})$-configuration, followed by the selection of the more representative conformations inside an energetic window of 4 kcal mol ${ }^{-1}$; (ii) further optimization at the AM1 semiempirical level of theory of the conformations selected from the MM search, again followed by selection of the structures found inside an energetic window of $1.2 \mathrm{kcal} \mathrm{mol}^{-1}$ (4 conformations), to which corresponds an overall Boltzmann population of 93.6\%; (iii) energy minimization performed in vacuum at the B3LYP/6-31G* level of theory of the four AM1 structures coming from the previous step, which collapsed to just one final conformation (maximum difference in energy stability amounting to $0.06 \mathrm{kcal} \mathrm{mol}^{-1}$ and Root-MeanSquare Deviation (RMSD) of atomic positions, with exclusion of the hydrogens, lesser than $0.3 \AA$ ); (iv) conclusive optimization at the $\mathrm{M} 06 / 6-31 \mathrm{G}^{*}$ level of theory of the most stable conformation found in the previous B3LYP minimization step; (v) quantum-mechanical simulation of both Electronic Circular Dichroism (ECD) and Optical Rotatory Dispersion (ORD) assessed for the conformation of 7 of $(\boldsymbol{R})$-configuration achieved in the previous fourth step.

The conformational search quoted in the first step of the procedure was carried out through MM calculations (force field: MMFF94), according to the systematic algorithm implemented in the computer program SPARTAN 10 v.1.1.0 (Wavefunction Inc., 18401 Von Karman Avenue, Suite 370, Irvine, CA 92612, USA). The conditions adopted in this analysis were: a) all the rotatable bonds varied; b) $40 \mathrm{~kJ} \times \mathrm{mol}^{-1}$ as maximum energy gap from the lowest energy geometry imposed for kept conformations; c) $\mathrm{R}^{2} \geq 0.9$ the criterion adopted to define conformers as duplicates in the analysis of similarity between conformations. Similarly, the structures optimizations mentioned in steps from 2 to 4 were again carried out by means of the program SPARTAN 10 v.1.1.0.

Instead, simulation of both ECD and ORD spectra have been performed through the algorithms implemented in the Amsterdam Density Functional (ADF) package v. 2007.01. The options set for such calculations were: single point at the BLYP level of theory, employing the QZ4P Large Core 
basis set; ethanol as the solvent; 30 singlet and triplet excitations; diagonalization method: Davidson; velocity representation; scaling factor 0.90 ; peak width 8.0. Optical Rotation values, $[\alpha]_{\mathrm{n}}$, have been assessed at six different wavelengths (n), in the range $400 \div 589 \mathrm{~nm}$. The found values, scaled of a factor 10, were: $[\alpha]_{400}=45.5^{\circ} ;[\alpha]_{438}=33.6^{\circ} ;[\alpha]_{476}=26.1^{\circ} ;[\alpha]_{513}=21.1^{\circ} ;[\alpha]_{551}=17.6^{\circ} ;[\alpha]_{589}=14.8^{\circ}$. The final simulated ECD and ORD spectra of $(\boldsymbol{R})-7$, superimposed on the experimental ones corresponding to the isolated enantiomers of 7, have been reported in Figure 7B and C. By inspection of the resulting plots, it can be reasonably inferred that to the first and second eluted enantiomers of 7 (green and red line in Figure 7B and C) have to be assigned the configurations $(\boldsymbol{R})$ and $(\boldsymbol{S})$, respectively.

\section{Acknowledgements}

MIUR is gratefully acknowledged for the grant PRIN 2017XYBP2R. This work was in part funded by the Researchers Supporting Project No. (RSP-2019/1) King Saud University, Riyadh, Saudi Arabia.

\section{- ABBREVIATIONS USED}

NP, Neuropathic pain; CAI, Carbonic Anhydrase Inhibitor; MOP, $\mu$-opioid receptor; H4R, histamine H4 receptor; KCC2, potassium-chloride cotransporter 2; SAR, structure-activity relationship; THF, tetrahydrofuran, CMC, carboxymethylcellulose.

\section{- AUTHOR INFORMATION}

*Corresponding Author:

Phone: +39-055-4573685. E-mail: alessio.nocentini@unifi.it (AN)

Phone: +39-055-4573729. Fax: +39-055-4573385. E-mail: claudiu.supuran@unifi.it (CTS)

\section{Supporting Information}


The Supporting Information is available free of charge on the ACS Publications website at DOI:

${ }^{1} \mathrm{H}-,{ }^{13} \mathrm{C}-,{ }^{31} \mathrm{P}-\mathrm{NMR}$ spectra, crystallographic data collection and refinement statistics, drug stability profiles in solution, HPLC chromatograms, in silico predicted ADMET properties. SMILES representation for compounds (CSV).

\begin{abstract}
Associated content
The atomic coordinates of the complexes have been deposited in the Protein Data Bank with accession codes 6SDS and 6SDT.
\end{abstract}

\title{
References
}

1. Finnerup, N.B.; Attal, N.; Haroutounian, S.; McNicol, E.; Baron, R.; Dworkin, R.H.; Gilron, I.; Haanpää, M.; Hansson, P.; Jensen, T.S.; Kamerman, P.R.; Lund, K.; Moore, A.; Raja, S.N.; Rice, A.S.; Rowbotham, M.; Sena, E.; Siddall, P.; Smith, B.H.; Wallace, M. Pharmacotherapy for neuropathic pain in adults: a systematic review and meta-analysis. Lancet Neurol. 2015, 14, 162-173. 2. Torrance, N.; Smith, B.H.; Bennett, M.I.; Lee, A.J. The epidemiology of chronic pain of predominantly neuropathic origin. Results from a general population survey. J. Pain 2006, 7, 281289.

3. Bouhassira, D.; Lantéri-Minet, M.; Attal, N.; Laurent, B.; Touboul, C. Prevalence of chronic pain with neuropathic characteristics in the general population. Pain 2008, 136, 380-387.

4. Watson, J.C.; Sandroni, P. Central neuropathic pain syndromes. Mayo. Clin. Proc. 2016, 91, 372385.

5. Wieseler-Frank, J.; Maier, S.F.; Watkins, L.R. Central proinflammatory cytokines and pain enhancement. Neuro-Signals 2005, 14, 166-174.

6. Bouhassira, D.; Attal, N. Translational neuropathic pain research: a clinical perspective. Neuroscience 2016, 338, 27-35. 
7. Dworkin, R.H.; O'Connor, A.B.; Audette, J.; Baron, R.; Gourlay, G.K.; Haanpää, M.L., Kent, J.L.; Krane, E.J.; LeBel, A.A.; Levy, R.M.; Mackey, S.C.; Mayer, J.; Miaskowski, C.; Raja, S.N.; Rice, A.S.C.; Schmader, K.E.; Stacey, B.; Stanos, S.; Treede, R.D.; Turk, D.C.; Walco, G.A.; Wells, C.D. Recommendations for the pharmacological management of neuropathic pain: an overview and literature update. Mayo Clinic Proceedings 2010, 85, S3-14.

8. Freeman, R. Newer agents for the treatment of painful diabetic peripheral neuropathy. Curr. Diab. Rep. 2005, 5, 409-416.

9. Snedecor, S.J.; Sudharshan, L.; Cappelleri, J.C.; Sadosky, A.; Mehta, S.; Botteman, M. Systematic review and meta-analysis of pharmacological therapies for painful diabetic peripheral neuropathy Pain Pract. 2014, 14, 167-184.

10. McDonald, A.A.; Portenoy, R.K.; How to use antidepressants and anticonvulsants as adjuvant analgesics in the treatment of neuropathic cancer pain. J. Support Oncol. 2006, 4, 43-52.

11. Di Cesare Mannelli, L.; Micheli, L.; Ghelardini, C. Nociceptin/orphanin FQ receptor and pain: Feasibility of the fourth opioid family member. Eur. J. Pharmacol. 2015, 766, 151-154.

12. Sanna, M.D.; Stark, H.; Lucarini, L.; Ghelardini, C.; Masini, E.; Galeotti, N. Histamine H4 receptor activation alleviates neuropathic pain through differential regulation of ERK, JNK, and P38 MAPK phosphorylation. Pain 2015, 156, 2492-2504.

13. (a) Di Cesare Mannelli, L.; Pacini, A.; Corti, F.; Boccella, S.; Luongo, L.; Esposito, E.; Cuzzocrea, S.; Maione, S.; Calignano, A.; Ghelardini C. Antineuropathic profile of N-palmitoylethanolamine in a rat model of oxaliplatin-induced neurotoxicity. PLoS One 2015, 10, e0128080; (b) González-Gil, I.; Zian, D.; Vázquez-Villa, H.; Hernández-Torres, G.; Martínez, RF.; Khiar-Fernández, N.; Rivera, R.; Kihara, Y.; Devesa, I.; Mathivanan, S.; Del Valle, CR.; Zambrana-Infantes, E.; Puigdomenech, M.; Cincilla, G.; Sanchez-Martinez, M.; Rodríguez de Fonseca, F.; Ferrer-Montiel, A.V.; Chun, J.; López-Vales, R.; López-Rodríguez, M.L.; Ortega-Gutiérrez, S. A novel agonist of the type 1 lysophosphatidic acid receptor (LPA1), UCM-05194, shows efficacy in neuropathic pain amelioration. J. Med. Chem. 2020, 63, 2372-2390. 
14. Carta, F.; Di Cesare Mannelli, L.; Pinard, M.; Ghelardini, C.; Scozzafava, A.; McKenna, R.; Supuran, C.T. A class of sulfonamide carbonic anhydrase inhibitors with neuropathic pain modulating effects. Bioorg. Med. Chem. 2015, 23, 1828-1840

15. Nocentini, A.; Donald, W.A.; Supuran, C.T. Human carbonic anhydrases: tissue distribution, physiologic role, and druggability. In Carbonic Anhydrases; Nocentini, A.; Supuran CT. Amsterdam: Elsevier; 2019. p. 149-185

16. Supuran, C.T. Carbonic anhydrases: novel therapeutic applications for inhibitors and activators. Nat. Rev. Drug. Discov. 2008, 7, 168-181.

17. Supuran, CT. Carbonic anhydrase inhibition and the management of neuropathic pain. Expert Rev. Neurother. 2016, 16, 961-968.

18. Halmi, P.; Parkkila, S.; Honkaniemi, J. Expression of carbonic anhydrases II, IV, VII, VIII and XII in rat brain after kainic acid induced status epilepticus. Neurochem. Int. 2006, 48, 24-30.

19. Asiedu, M.; Ossipov, M.H.; Kaila, K.; Price, T.J. Acetazolamide and midazolam act synergistically to inhibit neuropathic pain. Pain 2010, 148, 302-308.

20. Asiedu, M.N.; Mejia, G.L.; Hübner, C.A.; Kaila, K.; Price, T.J. Inhibition of carbonic anhydrase augments GABAA receptor-mediated analgesia via a spinal mechanism of action. J. Pain 2014, 15, 395-406.

21. Ruusuvuori, E.; Huebner, A.K.; Kirilkin, I.; Yukin, A.Y.; Blaesse, P.; Helmy, M.; Kang, H.J.; El Muayed, M.; Hennings, J.C.; Voipio, J.; Šestan, N.; Hübner, C.A.; Kaila, K. Neuronal carbonic anhydrase VII provides GABAergic excitatory drive to exacerbate febrile seizures. EMBO J. 2013, $32,2275-2286$

22. Ruusuvuori, E.; Kaila, K. Carbonic anhydrases and brain $\mathrm{pH}$ in the control of neuronal excitability. Subcell. Biochem. 2014, 75, 271-290

23. Nocentini, A.; Supuran, C.T. Advances in the structural annotation of human carbonic anhydrases and impact on future drug discovery. Expert Opin. Drug Discov. 2019, 14, 1175-1197. 
24. A Study of SLC-0111 and Gemcitabine for Metastatic Pancreatic Ductal Cancer in Subjects Positive for CAIX (SLC-0111-17-01) https://clinicaltrials.gov/ct2/show/NCT03450018 (accessed Dec 18, 2019).

25. Güzel, O.; Innocenti, A.; Scozzafava, A.; Salman, A.; Supuran, C.T. Carbonic anhydrase inhibitors. Phenacetyl-, pyridylacetyl- and thienylacetyl-substituted aromatic sulfonamides act as potent and selective isoform VII inhibitors. Bioorg. Med. Chem. Lett. 2009, 19, 3170-3173.

26. Alterio, V.; Hilvo, M.; Di Fiore, A.; Supuran, C.T.; Pan, P.; Parkkila, S.; Scaloni, A.; Pastorek, J.; Pastorekova, S.; Pedone, C.; Scozzafava, A.; Monti, S.M.; De Simone, G. Crystal structure of the catalytic domain of the tumor-associated human carbonic anhydrase IX. Proc. Natl. Acad. Sci. USA 2009, 106, 16233-16238.

27. Menchise, V.; De Simone, G.; Alterio, V.; Di Fiore, A.; Pedone, C.; Scozzafava, A.; Supuran, CT. Carbonic anhydrase inhibitors: stacking with Phe131 determines active site binding region of inhibitors as exemplified by the X-ray crystal structure of a membrane-impermeant antitumor sulfonamide complexed with isozyme II. J. Med. Chem. 2005, 48, 5721-5727.

28. Pacchiano, F.; Aggarwal, M.; Avvaru, B.S.; Robbins, A.H.; Scozzafava, A.; McKenna, R.; Supuran C.T. Selective hydrophobic pocket binding observed within the carbonic anhydrase II active site accommodate different 4-substituted-ureido-benzenesulfonamides and correlate to inhibitor potency. Chem. Commun (Camb). 2010, 46, 8371-8373.

29. Pacchiano, F.; Carta, F.; McDonald, P.C.; Lou, Y.; Vullo, D.; Scozzafava, A.; Dedhar, S.; Supuran, C.T. Ureido-substituted benzenesulfonamides potently inhibit carbonic anhydrase IX and show antimetastatic activity in a model of breast cancer metastasis. J. Med. Chem. 2011, 54, 18961902.

30. Nocentini, A.; Gratteri, P.; Supuran, C.T. Phosphorus versus sulfur: discovery of benzenephosphonamidates as versatile sulfonamide-mimic chemotypes acting as carbonic anhydrase inhibitors. Chem. Eur. J. 2019, 25, 1188-1192. 
31. Bourne, N.; Williams, A. Effect of basicity on the decomposition of the conjugate base of 4nitrophenyl N-aryl-P-phenylphosphonamidates. J. Chem. Soc., Perkin Transactions 2: Physical Organic Chemistry (1972-1999), 1985, 2, 265-268.

32. Khalifah, R.G. The carbon dioxide hydration activity of carbonic anhydrase. J. Biol. Chem. 1971, $246,2561-2573$.

33. De Simone, G.; Angeli, A.; Bozdag, M.; Supuran, C. T.; Winum, J. Y.; Monti, S. M.; Alterio, V. Inhibition of carbonic anhydrases by a substrate analog: benzyl carbamate directly coordinates the catalytic zinc ion mimicking bicarbonate binding. Chem. Commun. (Camb.) 2018, 54, 10312-10315. 34. De Simone, G.; Langella, E.; Esposito, D.; Supuran, C.T.; Monti, S.M.; Winum, J.Y.; Alterio, V. Insights into the binding mode of sulphamates and sulphamides to hCA II: crystallographic studies and binding free energy calculations. J. Enzyme Inhib. Med. Chem. 2017, 32, 1002-1011.

35. Alterio, V.; Cadoni, R.; Esposito, D.; Vullo, D.; Fiore, A.D.; Monti, S.M.; Caporale, A.; Ruvo, M.; Sechi, M.; Dumy, P.; Supuran, C.T.; De Simone, G.; Winum, J.Y. Benzoxaborole as a new chemotype for carbonic anhydrase inhibition. Chem. Commun. (Camb.) 2016, 52, 11983-11986.

36. http://www.chemicalize.com (accessed Dec 18, 2019).

37. https://preadmet.bmdrc.kr/ (accessed Mar 22, 2020).

38. Resta, F.; Micheli, L.; Laurino, A.; Spinelli, V.; Mello, T.; Sartiani, L.; Di Cesare Mannelli, L.; Cerbai, E.; Ghelardini, C.; Romanelli, M.N.; Mannaioni, G.; Masi, A. Selective HCN1 block as a strategy to control oxaliplatin-induced neuropathy. Neuropharmacology 2018, 131, 403-413.

39. Micheli, L.; Mattoli, L.; Maidecchi, A.; Pacini, A.; Ghelardini, C.; Di Cesare Mannelli, L. Effect of Vitis vinifera hydroalcoholic extract against oxaliplatin neurotoxicity: in vitro and in vivo evidence. Sci. Rep. 2018, 8, 14364. 
40. Di Cesare Mannelli, L.; Maresca, M.; Micheli, L.; Farina, C.; Scherz, M.W.; Ghelardini, C. A rat model of FOLFOX-induced neuropathy: effects of oral dimiracetam in comparison with duloxetine and pregabalin. Cancer Chemother Pharmacol. 2017, 80, 1091-1103.

41. Lavoie Smith, E.M.; Pang, H.; Cirrincione, C.; Fleishman, S.; Paskett, E.D.; Ahles, T.; Bressler, L.R.; Fadul, C.E.; Knox, C.; Le-Lindqwister, N.; Gilman, P.B.; Shapiro, C.L. Effect of duloxetine on pain, function, and quality of life among patients with chemotherapy-induced painful peripheral neuropathy: a randomized clinical trial. JAMA 2013, 309, 1359-1367.

42. Marshall, A.G.; Hendrickson, C.L. High-resolution mass spectrometers. Annu. Rev. Anal. Chem. 2008, 1, 579-599

43. Nocentini, A.; Trallori, E.; Singh, S.; Lomelino, C.L.; Bartolucci, G.; Di Cesare Mannelli, L.; Ghelardini, C.; McKenna, R.; Gratteri, P.; Supuran, C.T. 4-Hydroxy-3-nitro-5-ureidobenzenesulfonamides selectively target the tumor-associated carbonic anhydrase isoforms IX and XII showing hypoxia-enhanced antiproliferative profiles. J. Med. Chem. 2018, 61, 10860-10874.

44. Bonardi, A.; Vermelho, A.B.; da Silva Cardoso, V.; de Souza Pereira, M.C.; da Silva Lara, L.; Selleri, S.; Gratteri, P.; Supuran, C.T.; Nocentini, A. N-Nitrosulfonamides as carbonic anhydrase inhibitors: a promising chemotype for targeting Chagas disease and leishmaniasis. ACS Med. Chem. Lett. 2018, 10, 413-418.

45. Buonanno, M.; Di Fiore, A.; Langella, E.; D'Ambrosio, K.; Supuran, C. T.; Monti, S. M.; De Simone, G. The crystal structure of a hCA VII variant provides insights into the molecular determinants responsible for its catalytic behavior. Int. J. Mol. Sci. 2018, 19, E1571.

46. Di Fiore, A.; Truppo, E.; Supuran, C. T.; Alterio, V.; Dathan, N.; Bootorabi, F.; Parkkila, S.; Monti, S. M.; De Simone, G. Crystal structure of the C183S/C217S mutant of human CA VII in complex with acetazolamide. Bioorg. Med. Chem. Lett. 2010, 20, 5023-5026. 
47. Otwinowski, Z.; Minor, W. Processing of X-ray diffraction data collected in oscillation mode. Methods Enzymol. 1997, 276, 307-326.

48. Kovalevskiy, O.; Nicholls, R. A.; Long, F.; Carlon, A.; Murshudov, G. N. Overview of refinement procedures within REFMAC5: utilizing data from different sources. Acta Crystallogr. D Struct. Biol. 2018, 74, 215-227.

49. Groom, C. R.; Bruno, I. J.; Lightfoot, M. P.; Ward, S. C. The Cambridge structural database. Acta Crystallogr. B Struct. Sci. Cryst. Eng. Mater. 2016, 72, 171-179.

50. Schuttelkopf, A. W.; van Aalten, D. M. PRODRG: a tool for high-throughput crystallography of protein-ligand complexes. Acta Crystallogr. D Biol. Crystallogr. 2004, 60, 1355-1363.

51. Jones, T. A.; Zou, J. Y.; Cowan, S. W.; Kjeldgaard, M. Improved methods for building protein models in electron density maps and the location of errors in these models. Acta Crystallogr. A 1991, 47, 110-119.

52. Laskowski, R. A.; MacArthur, M. W.; Moss, D. S.; Thornton, J. M. PROCHECK: a program to check the stereochemical quality of protein structures. J. Appl. Crystallogr. 1993, 26, 283-291.

53. Hooft, R. W.; Vriend, G.; Sander, C.; Abola, E. E. Errors in protein structures. Nature 1996, 381, 272.

54. McGrath, J.C.; Lilley, E. Implementing guidelines on reporting research using animals (ARRIVE etc.): new requirements for publication in BJP. Br. J. Pharmacol. 2015, 172, 3189-3193.

55. Micheli, L.; Di Cesare Mannelli, L.; Rizzi, A.; Guerrini, R.; Trapella, C.; Calò, G.; Ghelardini, C. Intrathecal administration of nociceptin/orphanin FQ receptor agonists in rats: A strategy to relieve chemotherapy-induced neuropathic hypersensitivity. Eur. J. Pharmacol. 2015, 766, 155-162.

56. Baptista-de-Souza, D.; Di Cesare Mannelli, L.; Zanardelli, M.; Micheli, L.; Nunes-de-Souza, R.L.; Canto-de-Souza, A.; Ghelardini, C. Serotonergic modulation in neuropathy induced by oxaliplatin: effect on the 5HT2C receptor. Eur. J. Pharmacol. 2014, 735, 141-149. 


\section{TOC graphic}

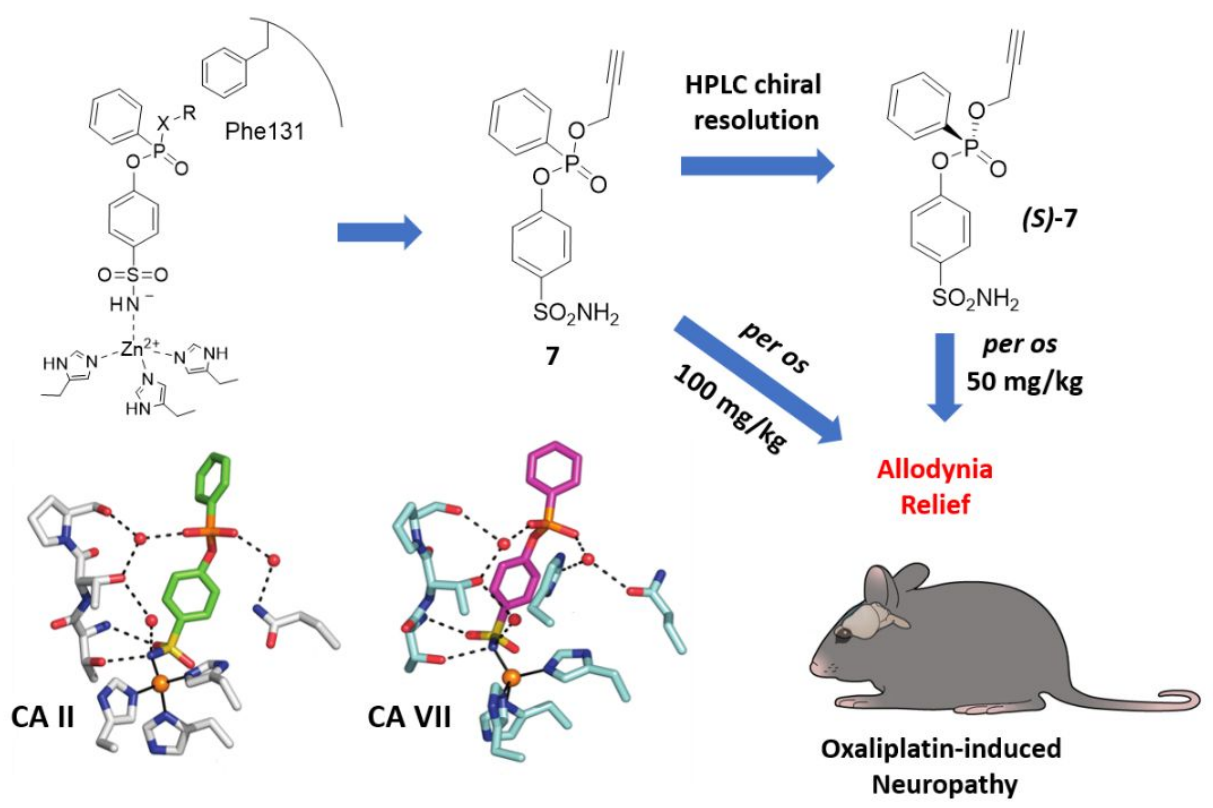

25

26 